NBER WORKING PAPER SERIES

\title{
INFORMATION AVOIDANCE AND IMAGE CONCERNS
}

\author{
Christine L. Exley \\ Judd B. Kessler \\ Working Paper 28376 \\ http://www.nber.org/papers/w28376 \\ NATIONAL BUREAU OF ECONOMIC RESEARCH \\ 1050 Massachusetts Avenue \\ Cambridge, MA 02138 \\ January 2021, Revised May 2021
}

For very helpful feedback on this paper, we thank Russell Golman, Zachary Grossman, Davide Pace, Matthew Rabin, Joshua Schwartzstein, Marta Serra Garcia, Joël van der Weele, and Roberto Weber. For funding, we thank Harvard Business School, the Wharton School, and the Wharton Behavioral Lab. The views expressed herein are those of the authors and do not necessarily reflect the views of the National Bureau of Economic Research.

NBER working papers are circulated for discussion and comment purposes. They have not been peer-reviewed or been subject to the review by the NBER Board of Directors that accompanies official NBER publications.

(C) 2021 by Christine L. Exley and Judd B. Kessler. All rights reserved. Short sections of text, not to exceed two paragraphs, may be quoted without explicit permission provided that full credit, including ( $)$ notice, is given to the source. 
Information Avoidance and Image Concerns

Christine L. Exley and Judd B. Kessler

NBER Working Paper No. 28376

January 2021, Revised May 2021

JEL No. C9,C91

\begin{abstract}
$\underline{\text { ABSTRACT }}$
A rich literature finds that individuals avoid information, even information that is instrumental to their choices. A common hypothesis posits that individuals strategically avoid information to hold particular beliefs or to take certain actions_-such as behaving selfishly-with lower image costs. Building off of the classic "moral wiggle room" design, this paper provides the first direct test of whether individuals avoid information because of image concerns. We do so by introducing a control condition that makes minimal changes to eliminate the role of image concerns while keeping other key features of the decision environment unchanged. We analyze data from 4,626 experimental subjects. We find that image concerns play a role in driving information avoidance, but a role that is substantially smaller-less than half of the magnitude - than the common approach in the literature would suggest.
\end{abstract}

Christine L. Exley

Harvard Business School

25 Baker Way

Baker Library 449

Boston, MA 02163

clexley@gmail.com

Judd B. Kessler

The Wharton School

University of Pennsylvania

3620 Locust Walk

Philadelphia, PA 19104

and NBER

judd.kessler@wharton.upenn.edu

A data appendix is available at http://www.nber.org/data-appendix/w28376 


\section{Introduction}

Why do individuals avoid information that could be instrumental to their decisions? A number of lines of research suggest that individuals avoid information in order to maintain certain beliefs (e.g., about themselves as healthy, financially responsible, politically enlightened, kind) even while taking actions that could suggest the opposite. Such explanations, however, rely on the sophistication of agents to strategically avoid information in order to maintain certain beliefs or in order to construct plausible deniability about their actions. In this paper, we introduce a new experimental approach to directly test whether individuals strategically avoid information because of image concerns.

We deploy our new approach in a context that has been the focus of a rich literature building off of Dana, Weber and Kuang (2007). In that seminal paper, a decision maker must choose between two options, A and B. Decision makers know that they earn more from choosing A but do not know whether $\mathrm{A}$ or $\mathrm{B}$ is better for another participant. They can avoid information and choose A or B directly, or they can learn which is better for the other participant before choosing. A set of results from that paper have proven to be robust and influential. First, individuals frequently avoid information on whether A or B is better for another participant. Second, individuals make substantially more selfish decisions (i.e., choosing A more often) when they can avoid information than in an alternative treatment when they cannot avoid information. Third, the fraction of individuals who avoid information is higher than the fraction of individuals who might be expected to avoid information because they do not value it (i.e., those who behave selfishly when information cannot be avoided). These findings have been replicated many times (Larson and Capra, 2009; Matthey and Regner, 2011; Feiler, 2014; Grossman, 2014; Exley, 2016; Grossman and van der Weele, 2017) and have raised an important debate about what drives passive information avoidance. ${ }^{1}$ A leading explanation in this context is image concerns - namely, self-image concerns given subjects' anonymity in prior work. Individuals might strategically avoid information so they can benefit themselves at lower image costs than they would pay if they acted selfishly after learning that benefiting themselves harmed others. ${ }^{2}$

The main contribution of this paper is our ability to directly test whether individuals strategically avoid information because of such image concerns. ${ }^{3}$ We compare the rates of information

\footnotetext{
${ }^{1}$ See conceptual replications in different paradigms (Kajackaite, 2015; Serra-Garcia and Szech, 2020).

${ }^{2}$ For important work on models of image concerns, see Rabin (1995); Bodner and Prelec (2003); Bénabou and Tirole (2004, 2006); Mijović-Prelec and Prelec (2010); Bénabou and Tirole (2011); Nyborg (2011); Grossman (2015); Grossman and van der Weele (2017); Bénabou, Falk and Tirole (2018); Foerster and van der Weele (2018). Significant empirical evidence supports the notion that image costs of acting selfishly are smaller when individuals do not know for certain they are being selfish. For reviews, see Bénabou and Tirole (2016) and Gino, Norton and Weber (2016). For the importance of direct tests to narrow in on underlying mechanisms, see Bartling, Fehr and Özdemir (2021).

${ }^{3} \mathrm{An}$ important related literature involves how individuals may strategically process information even when it is not avoided (Babcock et al., 1995; Gneezy, Saccardo and van Veldhuizen, 2018; Schwardmann, Tripodi and van der Weele, 2019; Gneezy et al., 2020; Saccardo and Serra-Garcia, 2020).
} 
avoidance in the classic Dana, Weber and Kuang (2007) setting to a new setting that makes minimal changes to remove image motives to avoid information; our new setting holds constant the structure of the decision, the content of the information, and the timing of information provision. We then attribute any difference in information avoidance across the two settings to image concerns.

In our new setting - our control condition - every aspect of the decision environment is the same as in the classic setting, except a different participant receives the payoff that would have gone to the decision maker. In this condition, image concerns cannot drive information avoidance. To see this, first note that image concerns about selfishness are clearly not relevant because the opportunity for selfishness is removed. Moreover, even other image concerns (e.g., a desire to appear fair) cannot drive information avoidance in our control condition. Individuals with such image concerns should instead acquire information and choose the option aligned with those image concerns, which they can do without suffering a financial cost. In our control condition, there is no chance that acquiring information will force a tradeoff between a choice motivated by image concerns and an option that benefits oneself, since no option benefits oneself. ${ }^{4}$

To see why a control condition like ours is necessary to explore whether image concerns drive information avoidance, consider the common approach in the prior literature for assessing the role of image concerns. It compares the rate of information avoidance when payoffs are unknown to the rate of selfishness when payoffs are known. The latter represents the fraction of subjects who may avoid information because they do not value it (since they will act selfishly regardless). But this difference does not identify the extent of information avoidance that is due to image concerns. First, selfish subjects could avoid information because they do not value it, or they could avoid information strategically to mitigate the image costs of their selfishness. Second, non-selfish subjects may avoid information for non-image reasons - such as laziness, inattention, or confusion-rather than image reasons. This is true even if these subjects end up acting selfishly when uninformed, and even if they enjoy the decreased image costs of acting selfishly; they could have avoided information for a non-image reason and then been happily surprised by the opportunity to benefit themselves without knowing for certain they were being selfish.

Our approach - using a control condition to compare information avoidance across a setting where it can be driven by image concerns and a similar setting where it cannot - thus differs from the common approach in the literature that compares rates of information avoidance to rates of selfishness. As further detailed in Section 2.2, our approach also differs from a rich literature that examines how other features of the decision environment influence rates of information avoidance but does not isolate the role of image concerns. ${ }^{5}$ Given the prevalence of information avoidance across domains, and the many lines of research exploring the motives of information avoidance,

\footnotetext{
${ }^{4}$ See section 2.1 for further discussion. Section 4.4 provides empirical evidence that our control condition does not introduce additional reasons to avoid information.

${ }^{5}$ See, for example, Grossman (2014); Grossman and van der Weele (2017); Serra-Garcia and Szech (2020).
} 
we see the use of a control condition like ours as an important methodological advance that could be applied more widely.

We deploy our control condition across four studies, including 4,626 experimental subjects. In each of these studies, we replicate the results of Dana, Weber and Kuang (2007). In each of these studies, we also find that a subset of subjects indeed avoid information due to image concerns. This evidence bolsters explanations of information avoidance as being due to image concerns in the extant literature, including the model and empirical evidence in support of the model presented in Grossman and van der Weele (2017).

Across our studies, however, we find that, at most, 19\%-34\% of information avoidance in the classic paradigm is due to image concerns. The $66 \%-81 \%$ residual is substantial, suggesting that the large majority of information avoidance in the classic paradigm cannot be attributed to image concerns. As shown in Section 3.2, our direct test estimates the role of strategic image concerns to be less than half of what the common approach in the literature would suggest. The remaining information avoidance arises for other reasons, potentially including a desire to avoid interpersonal tradeoffs, a desire to avoid learning bad news (e.g., that you cannot achieve your preferred payoffs), laziness, inattention, and confusion. We explore the empirical relevance of these motives in additional treatments, as detailed in Sections 4.1-4.3.

This analysis leads to two key take-aways. First, image concerns do indeed drive some information avoidance. Second, significantly less information avoidance is driven by image concerns than the common approach in the literature would suggest. The latter result highlights the value of our direct test of image concerns: it generates a different result than prior approaches.

We build off of the Dana, Weber and Kuang (2007) paradigm, and we replicate its findings and the findings of the literature that follows. That prior literature provides compelling evidence that the ability to act selfishly without knowing that an act was selfish facilitates more selfish behavior. To examine the extent to which the ability to avoid information influences selfish behavior, those prior studies have exactly the right set of treatments: one where information can be avoided and one where information cannot be avoided. We pursue a different identification approach because we are interested in a different question. We study why individuals avoid information, rather than the consequences of information avoidance. Better understanding the causes of information avoidance, and recognizing the large role that factors beyond strategic image concerns have in driving information avoidance, can help policymakers develop better methods for encouraging information acquisition when information is instrumental.

\section{Design}

This section describes the design of our main treatment conditions. Additional treatment conditions are introduced later.

A decision maker chooses between two options: Option A and Option B. The two options determine payoffs for two players, Player 1 and Player 2. The conditions under which a subject 
chooses between Option A and Option B vary according to the experimental treatment. In particular, in Study 1, subjects are randomly assigned to:

1. the Aligned or Unaligned state,

2. the Hidden Information or Known Information condition, and

3. the Self/Other or Other/Other condition.

How choices map to payoffs depends on the random assignment in (1). Table 1 shows payoffs by state. Our main treatments use the payoffs in the top panel, which we call the "Classic Payoffs" since they have the same structure as in Dana, Weber and Kuang (2007). ${ }^{6}$ Player 1 always earns more from Option A than from Option B, but Player 2 earns more from Option A in the Aligned state and earns more from Option B in the Unaligned state. Thus, in the unaligned state (and only the unaligned state), the decision maker faces a tradeoff in terms of benefiting Player 1 or benefiting Player 2.

Table 1: Payoffs for (Player 1, Player 2)

\begin{tabular}{|c|c|c|}
\hline \multicolumn{3}{|c|}{ Classic Payoffs with Online Participants (used in Studies 1, 2, and 3) } \\
\hline Option A & $\begin{array}{l}\text { Unaligned State } \\
(\$ 0.60, \$ 0.10)\end{array}$ & $\begin{array}{c}\text { Aligned State } \\
(\$ 0.60, \$ 0.50)\end{array}$ \\
\hline Option B & $(\$ 0.50, \$ 0.50)$ & $(\$ 0.50, \$ 0.10)$ \\
\hline \multicolumn{3}{|c|}{ Classic Payoffs with Penn Undergraduates (used in Study 4) } \\
\hline & Unaligned State & Aligned State \\
\hline Option A & $(\$ 6, \$ 1)$ & $(\$ 6, \$ 5)$ \\
\hline Option B & $(\$ 5, \$ 5)$ & $(\$ 5, \$ 1)$ \\
\hline \multicolumn{3}{|c|}{ New Payoffs with Online Participants (used in Studies 2 and 3) } \\
\hline & Aligned State 1 & Aligned State 2 \\
\hline Option A & $(\$ 0.50, \$ 0.10)$ & $(\$ 0.50, \$ 0.50)$ \\
\hline Option B & $(\$ 0.50, \$ 0.50)$ & $(\$ 0.50, \$ 0.10)$ \\
\hline
\end{tabular}

Each cell denotes the payoffs given to (Player 1, Player 2) according to whether Option A or Option $\mathrm{B}$ is chosen by the decision maker and according to the state. In the Self/Other condition, Player 1 is the decision maker and Player 2 is another participant. In the Other/Other condition, Players 1 and 2 are two other participants.

How information on payoffs is presented depends on the random assignment in (2). In the Known Information condition, subjects are directly informed of the state and the associated payoffs and are asked to choose between Option A and Option B directly. In the Hidden Information condition, subjects are informed of how the payoffs depend on the state and that there

\footnotetext{
${ }^{6}$ Given our online subject pool and study length, we divide their payoffs by 10 . In Section 3.3, we replicate our results in a traditional on-campus experimental lab with payoffs from Dana, Weber and Kuang (2007).
} 
is an equal chance of being assigned to either state. They are then asked whether they would like to: (i) choose Option A, (ii) choose Option B, or (iii) reveal which state they are in before choosing between Option A and Option B. We say subjects avoid information if they choose (i) or (ii) and acquire information if they choose (iii).

Whether the information avoidance in the Hidden Information condition may be driven by image concerns depends on the random assignment in (3). In the Self/Other condition, subjects know that they earn the Player 1 payoffs and another participant earns the Player 2 payoffs, implying that Option A always benefits themselves. This condition mirrors the classic paradigm in Dana, Weber and Kuang (2007); we call it the Self/Other condition to emphasize that the decision maker determines the payoff for themselves (i.e., Self) and for another participant (i.e., Other). In the Other/Other condition, subjects know that two other participants earn the Player 1 and Player 2 payoffs, implying that neither option benefits themselves. This is our new control condition in which image concerns can no longer drive information avoidance; we call it the Other/Other condition to emphasize that decisions only influence the payoffs of other participants.

\subsection{Why can't image concerns cause information avoidance in the Other/Other condition?}

The Other/Other condition removes selfish motives from the decision environment, which means image concerns about selfishness cannot drive information avoidance. The removal of selfish motives also prevents image concerns unrelated to selfishness, such as a desire to appear fair, from driving information avoidance in the Other/Other condition. A participant in the Self/Other condition may avoid information to avoid facing a tradeoff between appearing fair and money for themselves. A participant in the Other/Other condition who values appearing fair does not face this tradeoff between financial incentives and image concerns. This participant can simply acquire the information and then choose the option aligned with their image concerns. Consequently, while image concerns may cause participants to acquire information and influence whether participants choose A or B in the Other/Other condition, image concerns cannot cause participants to avoid information in the Other/Other condition.

Since the choice architecture, the content of the information, and the timing of information provision are all the same across the Self/Other and Other/Other conditions, we attribute the difference in information avoidance between these two conditions as being due to image concerns. One may wonder whether we have introduced other reasons for information avoidance in the Other/Other condition. In Section 4.4, we provide empirical evidence that replacing financial payoffs for the decision maker with financial payoffs for someone else does not have a direct effect on information avoidance. 


\subsection{Why is the Other/Other condition necessary?}

One may wonder whether we could have instead inferred the relevance of image concerns using data from the Hidden Information and Known Information conditions of the Self/Other condition only. Indeed, prior work often compares the rate of information avoidance in the Hidden Information condition to the rate of selfishness in the unaligned state in the Known Information condition. This prior work consistently finds that information avoidance is more common than selfishness and suggests that this difference between information avoidance and selfishness could be due to image concerns. This approach has - importantly - raised the debate about the motives for information avoidance. However, there are two reasons why this difference does not identify the role of image concerns in driving information avoidance.

The first is that individuals may avoid information because of image concerns even in settings when the information would not affect their choice. Consider an agent who always makes the most selfish choice. She may still decide to avoid information in the Hidden Information condition to appear less selfish, even though it does not change her behavior. Assuming that the difference between information avoidance and selfishness is due to image concerns ignores this possibility and could underestimate the extent to which image concerns drive information avoidance.

The second is that individuals who avoid information - and behave more selfishly as a resultin the Hidden Information condition could do so for reasons unrelated to image concerns. An agent who acts generously in the Known Information condition but who avoids information and acts selfishly in the Hidden Information condition may not have avoided information because of image concerns. She could have decided to avoid information for other reasons (e.g., inattention, confusion, laziness, a desire to avoid interpersonal tradeoffs, a desire to avoid bad news) but then acted selfishly (perhaps even enjoying the decreased image costs that came from being uninformed). Assuming that the difference between information avoidance and selfishness is due to image concerns ignores this possibility and could overestimate the extent to which image concerns drive information avoidance.

In addition, one may wonder whether other approaches in the prior literature have been able to isolate the impact of image concerns on information avoidance. Prior work has compellingly shown that rates of information avoidance can be affected by choice architecture, the content of information, and the timing of information provision. But this work does not isolate the role of image concerns in driving information avoidance. Changing the choice architecture, such as making information acquisition an active choice, could matter for image reasons - if avoiding information under an active choice is a stronger signal of selfishness - or for non-image reasons, such as laziness, inattention, and confusion. ${ }^{7}$ Changing the content of the information, as

\footnotetext{
${ }^{7}$ After documenting that requiring an active choice about information avoidance substantially reduces information avoidance, Grossman (2014) notes that one possible explanation - that should be examined in future work - is that the "active pursuit of ignorance" could be viewed as "more inappropriate socially." Moreover, prior work finds that individuals may use the possibility of inattention and confusion as excuses to behave selfishly
} 
frequently occurs when considering avoidance across contexts, could matter for image reasons - if image concerns are content-dependent - or because subjects differentially value different types of information. ${ }^{8}$ Changing the timing of information provision, such as providing it after the relevant decision has been made, could affect information avoidance for image reasons - if image costs of learning information are different when the information cannot be instrumental - or because of associated changes in choice architecture and the value of information. ${ }^{9}$ An important feature of our approach is that our Other/Other condition holds constant the choice architecture, the content of the information, and the timing of information provision while varying whether image concerns can drive information avoidance.

\subsection{Implementation Details}

Subjects were recruited on Amazon Mechanical Turk to complete Study 1 in July 2019. ${ }^{10}$ We recruited 800 subjects, and approximately 100 were randomly assigned to each of the eight treatment conditions (resulting from the $2 \times 2 \times 2$ design described above). We twice replicated the results from Study 1 by recruiting an additional 807 subjects in September 2019 (as part of Study 2) and an additional 796 subjects in February 2020 (as part of Study 3). These results from Studies 1-3 are detailed in Sections 3.1 and 3.2. In Section 3.3, we describe another replication with 222 undergraduate students from the University of Pennsylvania (as part of Study 4). In Section 4, we present additional design details and results, including treatment variations from Studies 2 and 3, involving another 2,003 subjects.

Prior to making any decision, subjects receive detailed instructions and must correctly answer understanding questions. See Appendix B for full experimental instructions and decision screens.

\section{Results}

In this section, we present results from Study 1 and the conditions of Studies $2-4$ that replicate Study 1.

\subsection{Replicating the original moral wiggle room findings}

Consistent with prior literature, we find that a large fraction of subjects avoid information in the Self/Other condition and that this fraction exceeds the rate of selfishness when information is known. Across the three studies, 0.67 (Study 1), 0.72 (Study 2), and 0.65 (Study 3) of subjects in the Hidden Information condition avoid information. Across the three studies, 0.32 (Study 1), 0.33 (Study 2), and 0.33 (Study 3) of subjects choose Option A - the selfish option-in the unaligned state of the Known Information condition.

(Exley and Kessler, 2019).

${ }^{8}$ As made clear in Serra-Garcia and Szech (2020), however, variations like these can be quite informative for other purposes, such as examining the elasticity of information avoidance.

${ }^{9}$ As made clear in Grossman and van der Weele (2017), however, variations like these can be quite informative for other purposes, such as providing empirical evidence in support of models with image concerns.

${ }^{10}$ Subjects needed a $95 \%$ approval rating or better from at least 100 prior HITs and a US IP address. For this 5 -minute study, subjects received $\$ 0.50$ plus any additional payoffs. 
Also replicating prior literature, we find that the ability to avoid information leads to more selfish behavior. As shown in Appendix Table A.1, which focuses on results from the unaligned state, the rates of choosing Option A increase by at least 20 percentage points in the Hidden Information condition when compared to the Known Information condition. Across the three studies, 0.56 (Study 1), 0.59 (Study 2), and 0.53 (Study 3) of subjects chose Option A in the unaligned state of the Hidden Information condition.

\subsection{Do individuals avoid information because of image concerns?}

The prior section shows that, when information can be avoided, individuals frequently avoid information and that more selfish behavior follows. To what extent can this be explained by subjects in the Self/Other condition avoiding information because of image concerns?

Table 2 shows results from all of our Hidden Information conditions. It presents a linear probability model of whether subjects avoid information on an indicator for whether subjects are randomly assigned to the Other/Other condition. The coefficient estimates on the constant show the rates of information avoidance in the Self/Other conditions. As noted in the prior section, these rates of information avoidance are high. The significant negative coefficient on the Other/Other indicator shows that we document significantly less information avoidance when image concerns cannot drive such avoidance. But the magnitude of these estimates, relative to the constant, implies that the minority of information avoidance in the Self/Other condition is due to image concerns. The percentage due to image concerns is $\frac{0.13}{0.67}=19 \%$ in Study $1, \frac{0.17}{0.72}=24 \%$ in Study 2, and $\frac{0.14}{0.65}=22 \%$ in Study 3. Equivalently, a large majority of the information avoidance observed in the Self/Other condition is not due to image concerns: $\frac{0.54}{0.67}=81 \%$ in Study 1, $\frac{0.55}{0.72}=76 \%$ in Study 2, and $\frac{0.51}{0.65}=78 \%$ in Study 3. In light of this large residual, we consider additional drivers of information avoidance in Section 4.

Table 2: Linear probability model of the likelihood of avoiding information

\begin{tabular}{|c|c|c|c|c|}
\hline & Study 1 & Study 2 & Study 3 & Study 4 \\
\hline Other/Other & $\begin{array}{c}-0.13^{* * *} \\
(0.05)\end{array}$ & $\begin{array}{c}-0.17^{* * *} \\
(0.05)\end{array}$ & $\begin{array}{c}-0.14^{* * *} \\
(0.05)\end{array}$ & $\begin{array}{c}-0.21^{* * *} \\
(0.07)\end{array}$ \\
\hline Constant & $\begin{array}{c}0.67^{* * *} \\
(0.03)\end{array}$ & $\begin{array}{c}0.72^{* * *} \\
(0.03)\end{array}$ & $\begin{array}{c}0.65^{* * *} \\
(0.03)\end{array}$ & $\begin{array}{c}0.62^{* * *} \\
(0.05)\end{array}$ \\
\hline $\mathrm{N}$ & 397 & 399 & 386 & 222 \\
\hline
\end{tabular}

${ }^{*} p<0.10,{ }^{* *} p<0.05,{ }^{* * *} p<0.01$. Standard errors are robust and shown in parentheses. The results are from a linear probability model of avoiding information, where Other/Other is an indicator for being the Other/Other condition. In all columns, the data are restricted to the decisions made in the unaligned or aligned state of the Hidden Information condition. In columns 1, 2, 3, and 4, the data are restricted to the decisions made in Study 1, 2, 3, or 4, respectively.

Our identification strategy suggests that a smaller fraction of information avoidance is due to image concerns than we would have guessed if we had followed the standard approach for 
identifying image concerns in the prior literature, as discussed in Section 2.2. In the Self/Other condition, the fraction of participants who avoid information in the Hidden Information condition minus the fraction of participants who choose Option A in the unaligned state of the Known Information condition is $0.67-0.33=0.34$ (Study 1), $0.72-0.32=0.40$ (Study 2), and $0.65-0.32=0.33$ (Study 3). These calculations would imply that image concerns account for a majority of information avoidance: $\frac{0.34}{0.67}=51 \%$ in Study $1, \frac{0.40}{0.72}=56 \%$ in Study 2, and $\frac{0.33}{0.65}=51 \%$ in Study 3. These percentages are all over twice as large as the percentages of information avoidance that we attribute to image concerns in the prior paragraph. Thus, not only is our comparison of the Self/Other to Other/Other conceptually different than this alternative approach, it is a difference that proves empirically important.

\subsection{Do our results replicate with undergraduate students?}

One may wonder whether our results were driven by our subjects being recruited from Amazon Mechanical Turk. Such concerns may be alleviated by our replication of the results from prior work (see Section 3.1) and our replication of our results from Study 1 twice (i.e., in Study 2 and Study 3).

Nonetheless, for Study 4 we recruited 222 undergraduates from the Wharton Behavioral Lab at the University of Pennsylvania. There are two main differences with the design of Study 4 relative to the designs for Studies 1-3. First, as shown in the middle panel of Table 1, we increased the value of payoffs to match the typical values used in this literature for undergraduate student subjects. Second, given the limited subject pool size, all subjects were assigned to one of the Hidden Information conditions (i.e., we excluded the Known Information conditions).

As shown in the Study 4 column of Table 2, our results persist. Information avoidance is substantial when subjects have a selfish motive to choose Option A. The coefficient estimates on the constant show that 0.62 of subjects avoid information in the Self/Other condition. In addition, the coefficient on Other/Other is large, negative and statistically significant $(p<0.01)$; information avoidance is 21 percentage points less likely when image concerns cannot drive avoidance. Based on our estimates, $\frac{0.21}{0.62}=34 \%$ of information avoidance from the Self/Other condition is attributable to image concerns and $\frac{0.41}{0.62}=66 \%$ arises for other reasons.

\section{Additional Results and Discussion}

Table 3 summarizes the rates of information avoidance across all of our Hidden Information conditions in all of our studies. The results shown in the first two columns were discussed in Section 3. In this section we report on additional treatments from Studies 2 and 3 to explore what-beyond image concerns - drives information avoidance. 
Table 3: Fraction avoiding information in Hidden Information conditions

\begin{tabular}{|c|c|c|c|c|c|c|}
\hline \multirow[t]{2}{*}{ Payoffs: } & \multicolumn{2}{|c|}{ Classic } & \multicolumn{2}{|c|}{ New } & \multicolumn{2}{|c|}{ New, Active Choice } \\
\hline & $S / O$ & $0 / O$ & $S / O-N e w$ & $\mathrm{O} / \mathrm{O}-\mathrm{New}$ & S/O-Active & O/O-Active \\
\hline Study 1 & 0.67 & 0.55 & & & . & . \\
\hline Study 2 & 0.72 & 0.55 & 0.44 & 0.43 & . & . \\
\hline Study 3 & 0.65 & 0.52 & 0.47 & 0.45 & 0.25 & 0.20 \\
\hline Study 4 & 0.62 & 0.41 & & . & . & . \\
\hline $\mathrm{N}$ & 698 & 706 & 400 & 391 & 199 & 197 \\
\hline
\end{tabular}

The first pair of columns involve the "Classic Payoffs" shown in the top panel of Table 1. The middle and last pair of columns involve the "New Payoffs" shown in the bottom panel of Table 1. The last pair of columns involve treatments where participants must actively choose whether or not to acquire information before having the ability to choose Option A or Option B. Within each pair of columns, results are split according to whether participants were randomly assigned to one of the conditions involving payoffs for themselves and another participant (i.e., the Self/Other, Self/Other-New, or Self/Other-Active condition) or one of the conditions involving payoffs for two other participants (i.e., the Other/Other, Other/Other-New, or Other/OtherActive condition). Note that $S / O$ and $O / O$ refer to the Self/Other and Other/Other conditions, respectively.

\subsection{Aversion to interpersonal tradeoffs or to learning "bad news"}

Image concerns cannot drive information avoidance in the Other/Other condition. So what does? One possibility is that participants do not want to be put into a position (like in the unaligned state) where they have to make a tradeoff between two participants, even if their own payoffs are not affected. Another possibility is that participants favor the payoffs they can achieve in one of the two states and so want to avoid learning for certain the "bad news" that they are in their less-preferred state (Golman, Hagmann and Loewenstein, 2017; Golman and Loewenstein, 2018).

To investigate whether these motives drive any residual information avoidance, we introduced new conditions in Studies 2 and 3. As shown in the bottom panel of Table 1, the "New Payoffs" are the same as the "Classic Payoffs" except that Option A gives $\$ 0.50$, rather than $\$ 0.60$, to Player 1. This change means the payoffs for the two players are always (weakly) aligned, eliminating concerns about aversion to interpersonal tradeoffs, and the two states are identical in what payoffs can be achieved, eliminating concerns that individuals may prefer one state to the other.

Consistent with a small role for aversion to interpersonal tradeoffs or bad news driving avoidance, Table 3 shows that the rates of information avoidance are 7-12 percentage points lower with the new payoffs (compare rates in the $O / O-N e w$ and $O / O$ columns). These differences are statistically significant in Study 2 (0.55 vs. $0.43, p<0.01)$ but only suggestive in Study $3(0.52$ vs. $0.45, p=0.23)$. Combining data from Studies 2 and 3 yields a significant difference ( 0.54 vs. $0.44, p<0.01)$. 
These results reinforce the value of replacing a self-other tradeoff with a comparable otherother tradeoff to explore the role of image concerns, rather than eliminating - or substantially changing - the involved tradeoff. If we had attempted to identify the role of image concerns by comparing information avoidance in the Self/Other and Self/Other-New conditions, we would have conflated the role of image concerns with the role of aversion to interpersonal tradeoffs or learning bad news.

\subsection{Choice architecture}

Results from the prior section suggest that substantial information avoidance cannot be attributed to image concerns, an aversion to making interpersonal tradeoffs, or the prospect of learning bad news. To explore this remaining information avoidance, we introduced an Active Choice version to the Hidden Information condition in Study 3. In this version, subjects again face the "New Payoffs," but prior to choosing Option A or B, subjects first have to actively choose whether to reveal or not reveal the state (see screenshot in Appendix Figure B.37).

As compared to the standard Hidden Information condition, the Active Choice version may reduce information avoidance for reasons surrounding confusion, inattention, and laziness. The active choice version makes the decision simpler, so confused subjects might better understand the value of revealing information. Inattentive subjects, such as those who choose somewhat randomly, should be less likely to avoid information in the active choice version where 1 of 2 options reveal information, rather than 1 of 3 in the standard version. Lazy subjects who avoided information in the standard version - by choosing Option A or B directly - to avoid having to click to a new screen and otherwise think more about the decision should be less likely to avoid information in the active choice version since they cannot skip the subsequent decision screen.

This change in the choice architecture proves powerful. As seen by comparing the "New" and "New, Active Choice" columns of Study 3 in Table 3, information avoidance is substantially lower when an active choice is required ( 0.25 vs. $0.47, p<0.01$, in the Self/Other condition; and 0.20 vs. $0.45, p<0.01$, in the Other/Other condition). These results echo those in Grossman (2014), which finds a similar effect of choice architecture in the classic paradigm when image concerns

may also be relevant. Our results complement the findings in that paper by demonstrating that choice architecture affects behavior, even independently of how it might affect image costs.

The results also reinforce the value of holding constant the choice architecture - and the related confusion, inattention, and laziness channels - in our control treatment that replaces a self-other tradeoff with a comparable other-other tradeoff.

\subsection{Indifference}

While the prior section posits a possible role of inattention, confusion, and laziness in driving information avoidance, results from our Known Information conditions suggest a limit to the empirical relevance of such explanations and - more broadly — to subjects being indifferent about 
others' payoffs.

As shown in Appendix Table A.2 (top panel, column 4), in the Aligned state of the Known Information condition, 98\% of subjects (pooling across all studies and conditions) choose Option A. That is, nearly all subjects choose the option that delivers higher payoffs to both players when they are directly informed of the payoff information, regardless of whether they are in the Self/Other or Other/Other condition.

Results with the new payoffs tell a similar story. Appendix Table A.2 (middle panel, columns 2 and 4 ) show that $92 \%$ of subjects (pooling across studies and conditions) choose the option that delivers higher payoffs to Player 2 (Option A in Aligned State 1 or Option B in Aligned State 2) in the Known Information condition. That is, when asked directly, over $90 \%$ of subjects choose the option that benefits other participants.

Thus, while the information avoidance decision may be more cognitively difficult than the choice of Option A or B in the Known Information conditions, it is clear from these Known Information choices that very few subjects are completely inattentive, confused, or indifferent.

\subsection{Does the Other/Other condition introduce additional motives for information avoidance?}

As noted above, the only change we make from the Self/Other condition to the Other/Other condition is switching the Player 1 payoffs from the decision maker to another subject. This change keeps constant the choice architecture, the content of information (i.e., the state-dependent payoffs for Player 2), the timing of information provision, and the possibility of a tradeoff between payoffs for Player 1 and Player 2 (i.e., in the unaligned state). We can thus compare information avoidance across these conditions to isolate the role of image concerns.

Nevertheless, one may wonder whether switching the Player 1 payoffs from the decision maker to another subject drives information avoidance for some other reason that is independent of its impact on image concerns, such as subjects being generally less engaged with the game when their own payoffs are not at stake. To assess this, we can explore how switching the Player 1 payoffs from the decision maker to another subject affects information avoidance when image concerns cannot drive information avoidance. We compare avoidance between Self/Other and Other/Other conditions under our "New Payoffs," in which image concerns cannot drive information avoidance because Player 1 always earns the same amount, regardless of the state or the decision maker's choice.

As shown in the middle two columns of Table 3, there is no difference in information avoidance across the Self/Other-New and Other/Other-New conditions. As shown in the right two columns of Table 3, the same pattern arises when comparing information avoidance across the Self/OtherActive and Other/Other-Active conditions. Indeed, in all of these comparisons, information avoidance is directionally lower in the Other/Other conditions than the equivalent Self/Other conditions, highlighting that switching the Player 1 payoffs from the decision maker to another 
subject is, if anything, inducing less information avoidance.

Thus, we observe no evidence of the Other/Other condition inducing additional reasons to avoid information that are not relevant in the Self/Other condition. If anything, we find the opposite, implying that our main results may provide an upper bound on the extent to which image concerns drive information avoidance.

\section{Conclusion}

Our experiment explores the extent to which information avoidance is driven by image concerns. We focus on the classic Dana, Weber and Kuang (2007) paradigm. We provide evidence of more information avoidance when image concerns could motivate information avoidance, highlighting that some subjects indeed avoid information because of image concerns. But, we also show how the common approach in the literature misestimates the role of image concerns in driving information avoidance and that the majority of information avoidance cannot be attributed to image concerns. Central to our contribution is our ability - by replacing a self-other tradeoff with a comparable other-other tradeoff - to consider an environment where image concerns cannot drive information avoidance, but other factors that could drive information avoidance are held constant.

Our exploration of information avoidance opens up additional questions for future work, three of which we note here. First, our results highlight the potential insights gleaned by having a comparable "benchmark" level of information avoidance when assessing a particular driver of information avoidance. In the literature related to selfish motives, replacing a self-other tradeoff with a comparable other-other tradeoff allows for such a benchmark. In the broader information avoidance literature, even if a comparable benchmark is not attainable, some benchmark level of information avoidance will likely be informative. We find that significant information avoidance can arise due to choice architecture - perhaps related to inattention, confusion, or lazinessrather than image concerns or payoff preferences.

Second, our results suggest that it might be worthwhile to revisit the relevance of both image-driven and non-image-driven motives in a range of other contexts in which information avoidance is prevalent (see Golman, Hagmann and Loewenstein (2017) for an excellent review of information avoidance across contexts). ${ }^{11}$ While we were surprised by the extent of information avoidance in the classic paradigm that could not be attributed to image concerns, we suspect there are many contexts where one may be surprised by the extent to which image concerns drive information avoidance. We hope future work jointly considers reasons related to image concerns and not related to image concerns to bolster our understanding of information avoidance and other avoidance decisions (e.g., when individuals avoid the ask or avoid making decisions). ${ }^{12}$

\footnotetext{
${ }^{11}$ Interesting questions also remain on how individuals seek information (see, e.g., Spiekermann and Weiss (2016)) for image and non-image reasons.

${ }^{12}$ For work related to how people avoid opportunities to be generous see, e.g., Dana, Cain and Dawes (2006);
} 
Third, and related, our work suggests gains from further exploring inattention, laziness, and confusion as potentially important drivers of information avoidance across a number of domains. It is possible that people rationally avoid information in response to problem complexity as in models of rational inattention and sparsity (Sims, 2003; Gabaix, 2014, 2017), that they avoid information because they look at problems the wrong way (see Handel and Schwartzstein (2018) for an excellent review), or even that the ability to avoid information provides individuals with an "excuse" not to fully think through decisions. While we have shown that image concerns can explain part of the information avoidance in a classic paradigm, much information avoidance remains. We see great promise in exploring the other drivers of information avoidance across domains. $^{13}$

Broberg, Ellingsen and Johannesson (2007); Jacobsen et al. (2011); DellaVigna, List and Malmendier (2012); Lazear, Malmendier and Weber (2012); Trachtman et al. (2015); Andreoni, Rao and Trachtman (2016); Lin, Schaumberg and Reich (2016).

${ }^{13}$ Indeed, many interesting questions remain about the conditions under which image concerns prove relevant, particularly given the findings in van der Weele et al. (2014). 


\section{References}

Andreoni, James, Justin M. Rao, and Hannah Trachtman. 2016. "Avoiding the ask: A field experiment on altruism, empathy, and charitable giving." Journal of Political Economy.

Babcock, Linda, George Loewenstein, Samuel Issacharoff, and Colin Camerer. 1995. "Biased Judgments of Fairness in Bargaining." The American Economic Review, 85(5): 13371343.

Bartling, Björn, Ernst Fehr, and Yagiz Özdemir. 2021. "Does Market Interaction Erode Moral Values?" Review of Economics and Statistic.

Bénabou, Roland, and Jean Tirole. 2004. "Willpower and personal rules." Journal of Political Economy, 112(4): 848-886.

Bénabou, Roland, and Jean Tirole. 2006. "Incentives and Prosocial Behavior." American Economic Review, 96(5): 1652-1678.

Bénabou, Roland, and Jean Tirole. 2011. "Identity, Morals, and Taboos: Beliefs as Assets." Quarterly Journal of Economics, 126: 805-855.

Bénabou, Roland, and Jean Tirole. 2016. "Mindful Economics: The Production, Consumption, and Value of Beliefs." Journal of Economic Perspectives, 30(3): 141-164.

Bénabou, Roland, Armin Falk, and Jean Tirole. 2018. "Narratives, Imperatives and Moral Reasoning." Working Paper.

Bodner, Ronit, and Drazen Prelec. 2003. "Self-signaling and diagnostic utility in everyday decision making." The psychology of economic decisions, 1: 105-26.

Broberg, Tomas, Tore Ellingsen, and Magnus Johannesson. 2007. "Is generosity involuntary?" Economics Letters, 94(1): 32-37.

Dana, Jason, Daylian M. Cain, and Robyn M. Dawes. 2006. "What you don't know won't hurt me: Costly (but quiet) exit in dictator games." Organizational Behavior and Human Decision Processes, 100: 193-201.

Dana, Jason, Roberto A. Weber, and Jason Xi Kuang. 2007. "Exploiting moral wiggle room: experiments demonstrating an illusory preference for fairness." Economic Theory, 33: $67-80$.

DellaVigna, Stefano, John List, and Ulrike Malmendier. 2012. "Testing for Altruism and Social Pressure in Charitable Giving." Quarterly Journal of Economics, 127(1): 1-56. 
Exley, Christine L. 2016. "Excusing Selfishness in Charitable Giving: The Role of Risk." Review of Economic Studies, 83(2): 587-628.

Exley, Christine L., and Judd B. Kessler. 2019. "Motivated Errors." Working Paper NBER No. 26595.

Feiler, Lauren. 2014. "Testing Models of Information Avoidance with Binary Choice Dictator Games." Journal of Economic Psychology.

Foerster, Manuel, and Joel J van der Weele. 2018. "Denial and Alarmism in Collective Action Problems." Working Paper.

Gabaix, Xavier. 2014. "A sparsity-based model of bounded rationality." The Quarterly Journal of Economics, 129(4): 1661-1710.

Gabaix, Xavier. 2017. "Behavioral Inattention." In Handbook of Behavioral Economics: Applications and Foundations 1. Vol. 2, 261-343. Elsevier.

Gino, Francesca, Michael I. Norton, and Roberto A. Weber. 2016. "Motivated Bayesians: Feeling Moral While Acting Egoistically." Journal of Economic Perspectives, 30(3): 189-212.

Gneezy, Uri, Silvia Saccardo, and Roel van Veldhuizen. 2018. "Bribery: Behavioral Drivers of Distorted Decisions." Journal of the European Economic Association.

Gneezy, Uri, Silvia Saccardo, Marta Serra-Garcia, and Roel van Veldhuizen. 2020. "Bribing the Self." Games and Economic Behavior, 120: 917-946.

Golman, Russell, and George Loewenstein. 2018. "Information gaps: A theory of preferences regarding the presence and absence of information." Decision, 5(3).

Golman, Russell, David Hagmann, and George Loewenstein. 2017. "Information Avoidance." Journal of Economic Literature, 55(1): 1-40.

Grossman, Zachary. 2014. "Strategic ignorance and the robustness of social preferences." Management Science, 60(11): 2659-2665.

Grossman, Zachary. 2015. "Self-signaling and social-signaling in giving." Journal of Economic Behavior \& Organization, 117(0): 26-39.

Grossman, Zachary, and Joël J van der Weele. 2017. "Self-image and willful ignorance in social decisions." Journal of the European Economic Association, 15(1). 
Handel, Benjamin, and Joshua Schwartzstein. 2018. "Frictions or Mental Gaps: What's Behind the Information We (Don't) Use and When Do We Care?" Journal of Economic Perspectives, 32(1): 155-178.

Jacobsen, Karin J, Kari H Eika, Leif Helland, Jo Thori Lind, and Karine Nyborg. 2011. "Are nurses more altruistic than real estate brokers?" Journal of Economic Psychology, 32(5): 818-831.

Kajackaite, Agne. 2015. "If I close my eyes, nobody will get hurt. The effect of ignorance on performance in a real effort experiment." Journal of Economic Behavior and Organization, 116: 518-524.

Larson, Tara, and Monica C. Capra. 2009. "Exploiting moral wiggle room: Illusory preference for fairness? A comment." Judgment and Decision Making, 4(6): 467-474.

Lazear, Edward P., Ulrike Malmendier, and Roberto A. Weber. 2012. "Sorting in experiments with application to social preferences." American Economic Journal: Applied Economics, 4(1): 136-163.

Lin, Stephanie C., Rebecca L. Schaumberg, and Taly Reich. 2016. "Sidestepping the rock and the hard place: The private avoidance of prosocial requests." Journal of Experimental Social Psychology, 35-40.

Matthey, Astrid, and Tobias Regner. 2011. "Do I really want to know? A cognitive dissonance-based explanation of other-regarding behavior." Games, 2(1): 114-135.

Mijović-Prelec, Danica, and Drazen Prelec. 2010. "Self-deception as self-signalling: a model and experimental evidence." Philosophical Transactions of the Royal Society B: Biological Sciences, 365(1538): 227-240.

Nyborg, Karine. 2011. "I don't want to hear about it: Rational ignorance among duty-oriented consumers." Journal of Economic Behavior \& Organization, 79(3): 263-274.

Rabin, M. 1995. "Moral preferences, moral constraints, and self-serving biases." Working paper.

Saccardo, Silvia, and Marta Serra-Garcia. 2020. "Cognitive Flexibility or Moral Commitment? Evidence of Anticipated Belief Distortion." Working Paper.

Schwardmann, Peter, Egon Tripodi, and Joël J. van der Weele. 2019. "Self-Persuasion: Evidence from Field Experiments at Two International Debating Competitions." Working Paper. 
Serra-Garcia, Marta, and Nora Szech. 2020. "The (in)elasticity of moral ignorance." Working Paper.

Sims, Christopher A. 2003. "Implications of rational inattention." Journal of Monetary Economics, 50(3): 665-690.

Spiekermann, Kai, and Arne Weiss. 2016. "Objective and subjective compliance: A normbased explanation of 'moral wiggle room'." Games and Economic Behavior, 96: 170-183.

Trachtman, Hannah, Andrew Steinkruger, Mackenzie Wood, Adam Wooster, James Andreoni, James J. Murphy, and Justin M. Rao. 2015. "Fair weather avoidance: unpacking the costs and benefits of "Avoiding the Ask"." Journal of the Economic Science Association, 1-7.

van der Weele, Joël J., Julija Kulisa, Michael Kosfeld, and Guido Friebel. 2014. "Resisting Moral Wiggle Room: How Robust Is Reciprocal Behavior?" American Economic Journal: Microeconomics, 6(3): 256-264. 


\section{APPENDICES (FOR ONLINE PUBLICATION ONLY) A Additional Tables}

Table A.1: Linear probability model of the likelihood of choosing Option A

\begin{tabular}{|c|c|c|c|}
\hline & Study 1 & Study 2 & $\overline{\text { Study } 3}$ \\
\hline Hidden Information & $\begin{array}{c}0.23^{* * *} \\
(0.07)\end{array}$ & $\begin{array}{c}0.27^{* * *} \\
(0.07)\end{array}$ & $\begin{array}{c}0.20^{* * *} \\
(0.07)\end{array}$ \\
\hline Constant & $\begin{array}{c}0.33^{* * *} \\
(0.05)\end{array}$ & $\begin{array}{c}0.32^{* * *} \\
(0.05)\end{array}$ & $\begin{array}{c}0.33^{* * *} \\
(0.05)\end{array}$ \\
\hline $\mathrm{N}$ & 199 & 200 & 200 \\
\hline
\end{tabular}

${ }^{*} p<0.10,{ }^{* *} p<0.05,{ }^{* * *} p<0.01$. Standard errors are robust and shown in parentheses. The results are from a linear probability model of the likelihood of choosing Option A, where Hidden Information is an indicator for being the Hidden Information condition. In all columns, the data are restricted to the decisions made in the Unaligned state of the Self/Other, Hidden Information condition or the Unaligned state of the Self/Other, Known Information condition. 
Table A.2: Fraction choosing Option A

\begin{tabular}{|c|c|c|c|c|}
\hline & \multicolumn{2}{|c|}{ Unaligned State } & \multicolumn{2}{|c|}{ Aligned State } \\
\hline & Hidden & Known & Hidden & Known \\
\hline & Information & Information & Information & Information \\
\hline \multicolumn{5}{|l|}{ Classic Payoffs } \\
\hline Study 1: Self/Other & 0.56 & 0.33 & 0.87 & 1.00 \\
\hline Study 1: Other/Other & 0.32 & 0.19 & 0.71 & 0.97 \\
\hline Study 2: Self/Other & 0.59 & 0.32 & 0.84 & 0.98 \\
\hline Study 2: Other/Other & 0.28 & 0.12 & 0.69 & 0.98 \\
\hline Study 3: Self/Other & 0.53 & 0.33 & 0.78 & 0.95 \\
\hline Study 3: Other/Other & 0.26 & 0.18 & 0.70 & 0.95 \\
\hline Study 4: Self/Other & 0.73 & & 0.96 & \\
\hline \multirow[t]{4}{*}{ Study 4: Other/Other } & 0.34 & . & 0.82 & \\
\hline & \multicolumn{2}{|c|}{ Aligned State 2} & \multicolumn{2}{|c|}{ Aligned State 1} \\
\hline & Hidden & Known & Hidden & Known \\
\hline & Information & Information & Information & Information \\
\hline \multicolumn{5}{|l|}{ New Payoffs } \\
\hline Study 2: Self/Other & 0.19 & 0.07 & 0.69 & 0.93 \\
\hline Study 2: Other/Other & 0.11 & 0.15 & 0.69 & 0.98 \\
\hline Study 3: Self/Other & 0.22 & 0.08 & 0.68 & 0.93 \\
\hline Study 3: Other/Other & 0.14 & 0.11 & 0.71 & 0.91 \\
\hline \multicolumn{5}{|c|}{ New Payoffs with Active Choice } \\
\hline Study 3: Self/Other & 0.25 & & 0.79 & \\
\hline Study 3: Other/Other & 0.29 & . & 0.86 & \\
\hline $\mathrm{N}$ & 1296 & 1018 & 1295 & 1019 \\
\hline
\end{tabular}

The above results show the fraction of participants choosing Option A, according to the treatment condition to which they were assigned. 


\section{B Experimental Instructions}

This paper involved four studies. Section B.1 presents the full instructions for Study 1. Section B.2 presents the full instructions for Study 2. Section B.3 presents the full instructions for Study 3. Section B.4 presents the full instructions for Study 4. We present the details of these studies by showing screenshots of our instructions and decision screens. While not shown in these screenshots - to facilitate readability (i.e., to allow the screenshots to be zoomed-in on the text) - each screen had a red arrow in the bottom right corner that subjects had to actively click to advance to the next page.

\section{B.1 Experimental Instructions for Study 1}

Participants in Study 1 were randomly assigned to 1 of 8 conditions that arise from (Hidden Information, Known Information $) \times($ Self/Other, Other/Other $) \times($ Unaligned state, Aligned state).

After consenting to participate in the study, subjects are informed of the $\$ 0.50$ study completion fee and of the opportunity to earn an additional payment. Figure B.1 shows how this payment information is explained and the corresponding comprehension question that each subject must answer correctly in order to proceed.

To mitigate the relevance of direct reciprocity concerns, in Study 1 (as well as in Studies 2 and 3), subjects are informed that they are randomly assigned into groups of three participants, that one member of their group will be randomly selected as the decision maker, and that only the choice of the decision maker will determine additional payoffs for the group. That is, the decision maker determines additional payoffs for themself and another group member in the Self/Other condition or for both of their other group members in the Other/Other condition. After subjects make their decisions, they fill out a short demographic survey. 
Figure B.1: Payment Information

Your payment: To complete this study, you must make one decision in a game and answer a short survey. For completing this study, you are guaranteed to receive 50 cents within 24 hours. Additional payment may also be given to you and/or other MTurk workers.

In particular, after all MTurk workers who are recruited for this study complete it, groups of three MTurk workers will be randomly formed. The other two MTurk workers in your group will be called "Player Y" and "Player Z." One member of each group will be randomly selected to be the "decision maker" in the game. Any additional payments that result from the decision made by the decision maker in the game will then be distributed within two weeks.

Understanding Question: Which of the following statements is true?

My decision will influence the additional payments from this study.

My decision will NOT influence the additional payments from this study.

My decision will influence the additional payments from this study if I am randomly selected to be the decision maker in my group. 
Participants are then provided with instructions about their decisions and asked to answer comprehension questions. Figures B.2-B.5 show the instructions and comprehension questions for each of the Known Information conditions. Figures B.6-B.7 show the instructions and comprehension questions for the Hidden Information conditions. 
Figure B.2: Known Information $\times$ Self/Other $\times$ Aligned State, Comprehension Questions

The game: You must choose A or B, which corresponds to payoffs for you and Player $Z$. Thus, the decision you make in this game will not influence payoffs for Player $Y$.

In particular:

- You will receive 60 cents if you choose A.

- You will receive $\mathbf{5 0}$ cents if you choose B.

- Player $\mathbf{Z}$ will receive $\mathbf{5 0}$ cents if you choose $\mathbf{A}$.

- Player Z will receive $\mathbf{1 0}$ cents if you choose B.

Put differently, according to whether you choose A or B, the payoffs for you and Player Z can be described as follows:

\begin{tabular}{|l|l|l|}
\hline & $\begin{array}{c}\text { You Will } \\
\text { Receive }\end{array}$ & $\begin{array}{c}\text { Player } \mathbf{Z} \text { Will } \\
\text { Receive }\end{array}$ \\
\hline A & 60 cents & 50 cents \\
\hline B & 50 cents & 10 cents \\
\hline
\end{tabular}

Understanding Question: You will receive more money if. . .

you choose $\mathrm{A}$.

you choose B.

Understanding Question: Player Z will receive more money if. . .

you choose A.

you choose B. 
Figure B.3: Known Information $\times$ Self/Other $\times$ Unaligned State, Comprehension Questions

The game: You must choose A or B, which corresponds to payoffs for you and Player Z. Thus, the decision you make in this game will not influence payoffs for Player $\mathrm{Y}$.

In particular:

- You will receive 60 cents if you choose A.

- You will receive $\mathbf{5 0}$ cents if you choose B.

- Player $\mathbf{Z}$ will receive $\mathbf{1 0}$ cents if you choose $\mathbf{A}$.

- Player $\mathbf{Z}$ will receive $\mathbf{5 0}$ cents if you choose $\mathbf{B}$.

Put differently, according to whether you choose A or B. the payoffs for you and Player Z can be described as follows:

\begin{tabular}{|l|l|l|}
\hline & $\begin{array}{c}\text { You Will } \\
\text { Receive }\end{array}$ & $\begin{array}{c}\text { Player } Z \text { Will } \\
\text { Receive }\end{array}$ \\
\hline A & 60 cents & 10 cents \\
\hline B & 50 cents & 50 cents \\
\hline
\end{tabular}

Understanding Question: You will receive more money if. . .

you choose $\mathrm{A}$.

you choose B.

Understanding Question: Player Z will receive more money if. . .

you choose $A$.

you choose $B$. 
Figure B.4: Known Information $\times$ Other/Other $\times$ Aligned State, Comprehension Questions

The game: You must choose A or B, which corresponds to payoffs for Player $\mathrm{Y}$ and Player $Z$. Thus, the decision you make in this game will not influence payoffs for you.

In particular:

- Player $\mathbf{Y}$ will receive 60 cents if you choose A.

- Player $\mathbf{Y}$ will receive $\mathbf{5 0}$ cents if you choose B.

- Player $\mathbf{Z}$ will receive $\mathbf{5 0}$ cents if you choose $\mathbf{A}$.

- Player $\mathbf{Z}$ will receive $\mathbf{1 0}$ cents if you choose $\mathbf{B}$.

Put differently, according to whether you choose A or B, the payoffs for Player $\mathrm{Y}$ and Player $Z$ can be described as follows:

\begin{tabular}{|l|c|c|}
\hline & $\begin{array}{c}\text { Player } Y \text { Will } \\
\text { Receive }\end{array}$ & $\begin{array}{c}\text { Player } Z \text { Will } \\
\text { Receive }\end{array}$ \\
\hline A & 60 cents & 50 cents \\
\hline B & 50 cents & 10 cents \\
\hline
\end{tabular}

Understanding Question: Player Y will receive more money if. . .

you choose $A$.

you choose B.

Understanding Question: Player Z will receive more money if. . .

you choose $A$.

you choose B. 
Figure B.5: Known Information $\times$ Other/Other $\times$ Unaligned State, Comprehension Questions

The game: You must choose A or B, which corresponds to payoffs for Player $\mathrm{Y}$ and Player $Z$. Thus, the decision you make in this game will not influence payoffs for you.

In particular:

- Player $\mathbf{Y}$ will receive $\mathbf{6 0}$ cents if you choose $\mathbf{A}$.

- Player $\mathbf{Y}$ will receive $\mathbf{5 0}$ cents if you choose B.

- Player $\mathbf{Z}$ will receive $\mathbf{1 0}$ cents if you choose $\mathbf{A}$.

- Player $\mathbf{Z}$ will receive $\mathbf{5 0}$ cents if you choose $\mathbf{B}$.

Put differently, according to whether you choose A or B. the payoffs for Player $Y$ and Player $Z$ can be described as follows:

\begin{tabular}{|c|c|c|}
\hline & $\begin{array}{c}\text { Player } Y \text { Will } \\
\text { Receive }\end{array}$ & $\begin{array}{c}\text { Player } Z \text { Will } \\
\text { Receive }\end{array}$ \\
\hline A & 60 cents & 10 cents \\
\hline B & 50 cents & 50 cents \\
\hline
\end{tabular}

Understanding Question: Player Y will receive more money if. . .

you choose $A$.

you choose B.

Understanding Question: Player Z will receive more money if. . .

you choose A.

you choose $B$. 
Figure B.6: Hidden Information × Self/Other, Comprehension Questions

The game: You must choose A or B, which corresponds to payoffs for you and Player Z. Thus, the decision you make in this game will not influence payoffs for Player $Y$.

There is a $50 \%$ chance that you are in GAME 1 and a $50 \%$ that you are in GAME 2.

Both games are the same except that Player Z's payoffs are flipped between the two games. In particular:

- You will receive 60 cents if you choose $\mathbf{A}$ in either game.

- You will receive $\mathbf{5 0}$ cents if you choose B in either game.

- Player $\mathbf{Z}$ will receive $\mathbf{1 0}$ cents if you choose $\mathbf{A}$ in GAME $\mathbf{1}$ or $\mathbf{B}$ in GAME 2.

- Player $\mathbf{Z}$ will receive $\mathbf{5 0}$ cents if you choose $\mathbf{B}$ in GAME $\mathbf{1}$ or $\mathbf{A}$ in GAME $\mathbf{2}$.

Put differently, according to whether you are in GAME 1 or GAME 2 and whether you choose A or B, the payoffs for you and Player $Z$ can be described as follows:

\begin{tabular}{|c|c|c|}
\hline & \multicolumn{2}{|c|}{ GAME 1 } \\
\hline & $\begin{array}{l}\text { You Will } \\
\text { Receive }\end{array}$ & $\begin{array}{c}\text { Player } Z \text { Will } \\
\text { Receive }\end{array}$ \\
\hline A & 60 cents & 10 cents \\
\hline B & 50 cents & 50 cents \\
\hline
\end{tabular}

\begin{tabular}{|c|c|c|}
\hline & \multicolumn{2}{|c|}{ GAME 2} \\
\hline & $\begin{array}{l}\text { You Will } \\
\text { Receive }\end{array}$ & $\begin{array}{c}\text { Player } Z \text { Will } \\
\text { Receive }\end{array}$ \\
\hline A & 60 cents & 50 cents \\
\hline B & 50 cents & 10 cents \\
\hline
\end{tabular}

Understanding Question: You will receive more money if. . .

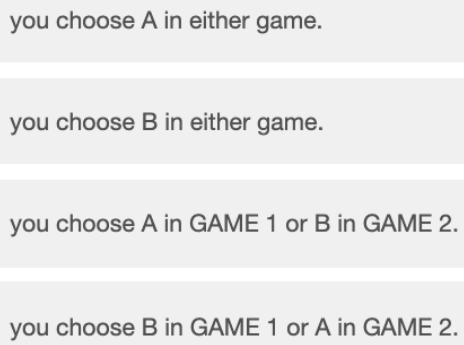

Understanding Question: Player Z will receive more money if. . .

you choose $\mathrm{A}$ in either game.

you choose B in either game.

you choose A in GAME 1 or B in GAME 2.

you choose B in GAME 1 or A in GAME 2. 
Figure B.7: Hidden Information $\times$ Other/Other, Comprehension Questions

The game: You must choose A or B, which corresponds to payoffs for Player $\mathrm{Y}$ and Player Z. Thus, the decision you make in this game will not influence payoffs for you.

There is a $50 \%$ chance that you are in GAME 1 and a $50 \%$ that you are in GAME 2.

Both games are the same except that Player Z's payoffs are flipped between the two games. In particular:

- Player $\mathbf{Y}$ will receive $\mathbf{6 0}$ cents if you choose $\mathbf{A}$ in either game.

- Player $\mathbf{Y}$ will receive $\mathbf{5 0}$ cents if you choose $\mathbf{B}$ in either game.

- Player $Z$ will receive $\mathbf{1 0}$ cents if you choose $A$ in GAME 1 or B in GAME 2.

- Player $\mathbf{Z}$ will receive $\mathbf{5 0}$ cents if you choose $\mathbf{B}$ in GAME 1 or $\mathbf{A}$ in GAME 2.

Put differently, according to whether you are in GAME 1 or GAME 2 and whether you choose $\mathrm{A}$ or $\mathrm{B}$, the payoffs for Player $\mathrm{Y}$ and Player $\mathrm{Z}$ can be described as follows:

\begin{tabular}{|c|c|c|}
\hline & \multicolumn{2}{|c|}{ GAME 1 } \\
\hline & $\begin{array}{c}\text { Player } Y \text { Will } \\
\text { Receive }\end{array}$ & $\begin{array}{c}\text { Player Z Will } \\
\text { Receive }\end{array}$ \\
\hline A & 60 cents & 10 cents \\
\hline B & 50 cents & 50 cents \\
\hline
\end{tabular}

\begin{tabular}{|c|c|c|}
\hline & \multicolumn{2}{|c|}{ GAME 2} \\
\hline & $\begin{array}{c}\text { Player } Y \text { Will } \\
\text { Receive }\end{array}$ & $\begin{array}{c}\text { Player Z Will } \\
\text { Receive }\end{array}$ \\
\hline A & 60 cents & 50 cents \\
\hline B & 50 cents & 10 cents \\
\hline
\end{tabular}

Understanding Question: Player Y will receive more money if. . .

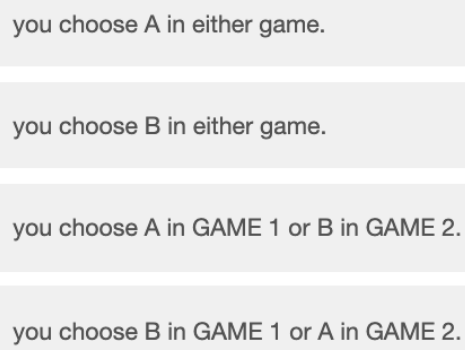

Understanding Question: Player Z will receive more money if. . .

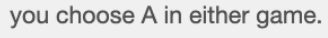


Participants are then reminded of the instructions and asked to make their decisions. Figures B.8-B.11 show the decision screens for each of the Known Information conditions. Figures B.12B.13 show the decision screens for each of the Hidden Information conditions. If participants in those conditions choose to Reveal Player Z's payoffs, then the state is revealed and they are asked to make their decision on the next page, as shown below in Figures B.14-B.17.

Figure B.8: Known Information $\times$ Self/Other $\times$ Aligned State, Decision

The game: You must choose A or B, which corresponds to payoffs for you and Player Z. Thus, the decision you make in this game will not influence payoffs for Player $\mathrm{Y}$.

In particular:

- You will receive 60 cents if you choose A.

- You will receive $\mathbf{5 0}$ cents if you choose B.

- Player $\mathbf{Z}$ will receive $\mathbf{5 0}$ cents if you choose $\mathbf{A}$.

- Player $\mathbf{Z}$ will receive $\mathbf{1 0}$ cents if you choose $\mathbf{B}$.

Put differently, according to whether you choose A or B, the payoffs for you and Player Z can be described as follows:

\begin{tabular}{|l|l|l|}
\hline & $\begin{array}{l}\text { You Will } \\
\text { Receive }\end{array}$ & $\begin{array}{c}\text { Player } \mathbf{Z} \text { Will } \\
\text { Receive }\end{array}$ \\
\hline A & 60 cents & 50 cents \\
\hline B & 50 cents & 10 cents \\
\hline
\end{tabular}

Now, please make your decision in this game (by choosing A or B) given that:

- If you choose A, you will receive 60 cents, and Player $Z$ will receive 50 cents.

- If you choose B, you will receive 50 cents, and Player $Z$ will receive 10 cents. 
Figure B.9: Known Information $\times$ Self/Other $\times$ Unaligned State, Decision

The game: You must choose A or B, which corresponds to payoffs for you and Player Z. Thus, the decision you make in this game will not influence payoffs for Player $\mathrm{Y}$.

In particular:

- You will receive 60 cents if you choose A.

- You will receive $\mathbf{5 0}$ cents if you choose $\mathbf{B}$.

- Player $\mathbf{Z}$ will receive $\mathbf{1 0}$ cents if you choose $\mathbf{A}$.

- Player $\mathbf{Z}$ will receive $\mathbf{5 0}$ cents if you choose $\mathbf{B}$.

Put differently, according to whether you choose A or B. the payoffs for you and Player Z can be described as follows:

\begin{tabular}{|c|c|c|}
\hline & $\begin{array}{l}\text { You Will } \\
\text { Receive }\end{array}$ & $\begin{array}{c}\text { Player } \mathbf{Z} \text { Will } \\
\text { Receive }\end{array}$ \\
\hline A & 60 cents & 10 cents \\
\hline$B$ & 50 cents & 50 cents \\
\hline
\end{tabular}

Now, please make your decision in this game (by choosing A or B) given that:

- If you choose $A$, you will receive 60 cents, and Player $Z$ will receive 10 cents.

- If you choose B, you will receive 50 cents, and Player $Z$ will receive 50 cents. 
Figure B.10: Known Information $\times$ Other $/$ Other $\times$ Aligned State, Decision

The game: You must choose A or B, which corresponds to payoffs for Player $\mathrm{Y}$ and Player $Z$. Thus, the decision you make in this game will not influence payoffs for you.

In particular:

- Player $\mathbf{Y}$ will receive $\mathbf{6 0}$ cents if you choose A.

- Player $\mathbf{Y}$ will receive $\mathbf{5 0}$ cents if you choose B.

- Player $\mathbf{Z}$ will receive $\mathbf{5 0}$ cents if you choose $\mathbf{A}$.

- Player $\mathbf{Z}$ will receive $\mathbf{1 0}$ cents if you choose $\mathbf{B}$.

Put differently, according to whether you choose A or B, the payoffs for Player $\mathrm{Y}$ and Player $Z$ can be described as follows:

\begin{tabular}{|l|c|c|}
\hline & $\begin{array}{c}\text { Player } \mathbf{Y} \text { Will } \\
\text { Receive }\end{array}$ & $\begin{array}{c}\text { Player } \mathbf{Z} \text { Will } \\
\text { Receive }\end{array}$ \\
\hline A & 60 cents & 50 cents \\
\hline B & 50 cents & 10 cents \\
\hline
\end{tabular}

Now, please make your decision in this game (by choosing A or B) given that:

- If you choose A, Player $Y$ will receive 60 cents, and Player $Z$ will receive 50 cents.

- If you choose B, Player $Y$ will receive 50 cents, and Player $Z$ will receive 10 cents. 
Figure B.11: Known Information $\times$ Other/Other $\times$ Unaligned State, Decision

The game: You must choose A or B, which corresponds to payoffs for Player $\mathrm{Y}$ and Player $Z$. Thus, the decision you make in this game will not influence payoffs for you.

In particular:

- Player $\mathbf{Y}$ will receive 60 cents if you choose $\mathbf{A}$.

- Player $\mathbf{Y}$ will receive $\mathbf{5 0}$ cents if you choose $\mathbf{B}$.

- Player $\mathbf{Z}$ will receive $\mathbf{1 0}$ cents if you choose $\mathbf{A}$.

- Player $\mathbf{Z}$ will receive $\mathbf{5 0}$ cents if you choose $\mathbf{B}$.

Put differently, according to whether you choose A or B. the payoffs for Player $Y$ and Player $Z$ can be described as follows:

\begin{tabular}{|c|c|c|}
\hline & $\begin{array}{c}\text { Player } Y \text { Will } \\
\text { Receive }\end{array}$ & $\begin{array}{c}\text { Player } Z \text { Will } \\
\text { Receive }\end{array}$ \\
\hline A & 60 cents & 10 cents \\
\hline B & 50 cents & 50 cents \\
\hline
\end{tabular}

Now, please make your decision in this game (by choosing A or B) given that:

- If you choose A, Player $Y$ will receive 60 cents, and Player $Z$ will receive 10 cents.

- If you choose B, Player $Y$ will receive 50 cents, and Player $Z$ will receive 50 cents. 
Figure B.12: Hidden Information $\times$ Self/Other, Decision

The game: You must choose A or B, which corresponds to payoffs for you and Player Z. Thus, the decision you make in this game will not influence payoffs for Player $\mathrm{Y}$.

There is a $50 \%$ chance that you are in GAME 1 and a $50 \%$ that you are in GAME 2.

Both games are the same except that Player Z's payoffs are flipped between the two games. In particular:

- You will receive 60 cents if you choose $\mathbf{A}$ in either game.

- You will receive $\mathbf{5 0}$ cents if you choose $\mathbf{B}$ in either game.

- Player $Z$ will receive 10 cents if you choose $A$ in GAME 1 or B in GAME 2.

- Player $\mathbf{Z}$ will receive $\mathbf{5 0}$ cents if you choose $\mathbf{B}$ in GAME 1 or A in GAME 2.

Put differently, according to whether you are in GAME 1 or GAME 2 and whether you choose $\mathrm{A}$ or $\mathrm{B}$, the payoffs for you and Player $\mathrm{Z}$ can be described as follows:

\begin{tabular}{|l|l|c|}
\hline & \multicolumn{2}{|c|}{ GAME 1 } \\
\hline & $\begin{array}{l}\text { You Will } \\
\text { Receive }\end{array}$ & $\begin{array}{c}\text { Player } \mathbf{Z} \text { Will } \\
\text { Receive }\end{array}$ \\
\hline A & 60 cents & 10 cents \\
\hline B & 50 cents & 50 cents \\
\hline
\end{tabular}

\begin{tabular}{|l|l|c|}
\hline & \multicolumn{2}{|c|}{ GAME 2} \\
\hline & $\begin{array}{l}\text { You Will } \\
\text { Receive }\end{array}$ & $\begin{array}{c}\text { Player } \mathbf{Z} \text { Will } \\
\text { Receive }\end{array}$ \\
\hline A & 60 cents & 50 cents \\
\hline B & 50 cents & 10 cents \\
\hline
\end{tabular}

Now, please make your decision in this game (by choosing A or B) or instead indicate that you would like to make your decision after being informed of which game you are in (by choosing Reveal Player Z's Payoffs) given that:

- If you choose A, you will receive 60 cents regardless of which game you are in, and Player $Z$ will receive 10 cents if you are in GAME 1 or 50 cents if you are in GAME 2.

- If you choose B, you will receive 50 cents regardless of which game you are in, and Player $Z$ will receive 50 cents if you are in GAME 1 or 10 cents if you are in GAME 2.

- If you choose Reveal Player Z's Payoffs, information on the next page will reveal whether you are in GAME 1 or GAME 2 and thus will reveal the exact payoffs that Player $\mathrm{Z}$ will receive if you choose $\mathrm{A}$ or $\mathrm{B}$. After this information is revealed, you will choose between $A$ and $B$. 
Figure B.13: Hidden Information $\times$ Other/Other, Decision

The game: You must choose $\mathrm{A}$ or $\mathrm{B}$, which corresponds to payoffs for Player $\mathrm{Y}$ and Player $Z$. Thus, the decision you make in this game will not influence payoffs for you.

There is a $50 \%$ chance that you are in GAME 1 and a $50 \%$ that you are in GAME 2.

Both games are the same except that Player Z's payoffs are flipped between the two games. In particular:

- Player $\mathbf{Y}$ will receive $\mathbf{6 0}$ cents if you choose $\mathbf{A}$ in either game.

- Player $\mathbf{Y}$ will receive $\mathbf{5 0}$ cents if you choose $\mathbf{B}$ in either game.

- Player $\mathbf{Z}$ will receive $\mathbf{1 0}$ cents if you choose $A$ in GAME 1 or B in GAME 2.

- Player $\mathbf{Z}$ will receive $\mathbf{5 0}$ cents if you choose $\mathbf{B}$ in GAME $\mathbf{1}$ or A in GAME 2.

Put differently, according to whether you are in GAME 1 or GAME 2 and whether you choose $\mathrm{A}$ or $\mathrm{B}$, the payoffs for Player $\mathrm{Y}$ and Player $\mathrm{Z}$ can be described as follows:

\begin{tabular}{|c|c|c|}
\hline & \multicolumn{2}{|c|}{ GAME 1 } \\
\hline & $\begin{array}{c}\text { Player } Y \text { Will } \\
\text { Receive }\end{array}$ & $\begin{array}{c}\text { Player } Z \text { Will } \\
\text { Receive }\end{array}$ \\
\hline A & 60 cents & 10 cents \\
\hline B & 50 cents & 50 cents \\
\hline
\end{tabular}

\begin{tabular}{|c|c|c|}
\hline & \multicolumn{2}{|c|}{ GAME 2} \\
\hline & $\begin{array}{c}\text { Player } Y \text { Will } \\
\text { Receive }\end{array}$ & $\begin{array}{c}\text { Player } \mathbf{Z} \text { Will } \\
\text { Receive }\end{array}$ \\
\hline A & 60 cents & 50 cents \\
\hline B & 50 cents & 10 cents \\
\hline
\end{tabular}

Now, please make your decision in this game (by choosing A or B) or instead indicate that you would like to make your decision after being informed of which game you are in (by choosing Reveal Player Z's Payoffs) given that:

- If you choose A, Player $Y$ will receive 60 cents regardless of which game you are in, and Player $Z$ will receive 10 cents if you are in GAME 1 or 50 cents if you are in GAME 2.

- If you choose B, Player $Y$ will receive 50 cents regardless of which game you are in, and Player $Z$ will receive 50 cents if you are in GAME 1 or 10 cents if you are in GAME 2.

- If you choose Reveal Player Z's Payoffs, information on the next page will reveal whether you are in GAME 1 or GAME 2 and thus will reveal the exact payoffs that Player $Z$ will receive if you choose $A$ or $B$. After this information is revealed, you will choose between $\mathrm{A}$ and $\mathrm{B}$. 
Figure B.14: Hidden Information $\times$ Self/Other $\times$ Aligned Condition, After Revealing Player Z's Payoffs

You chose to Reveal Player Z's Payoffs. Note that you are in GAME 2 and thus:

- You will receive 60 cents if you choose A.

- You will receive $\mathbf{5 0}$ cents if you choose B.

- Player $\mathbf{Z}$ will receive $\mathbf{5 0}$ cents if you choose $\mathbf{A}$.

- Player $\mathbf{Z}$ will receive $\mathbf{1 0}$ cents if you choose B.

Put differently, since you are in GAME 2, according to whether you choose A or B, the payoffs for you and Player $Z$ can be described as follows:

\begin{tabular}{|l|l|c|}
\hline & \multicolumn{2}{|c|}{ GAME 2} \\
\hline & $\begin{array}{l}\text { You Will } \\
\text { Receive }\end{array}$ & $\begin{array}{c}\text { Player } \mathbf{Z} \text { Will } \\
\text { Receive }\end{array}$ \\
\hline A & 60 cents & 50 cents \\
\hline B & 50 cents & 10 cents \\
\hline
\end{tabular}

Now, please make your decision in this game (by choosing A or B) given that:

- If you choose A, you will receive 60 cents, and Player $Z$ will receive 50 cents.

- If you choose B, you will receive 50 cents, and Player $Z$ will receive 10 cents. 
Figure B.15: Hidden Information $\times$ Self/Other $\times$ Unaligned State, After Revealing Player Z's Payoffs

You chose to Reveal Player Z's payoffs. Note that you are in GAME 1 and thus:

- You will receive 60 cents if you choose A.

- You will receive $\mathbf{5 0}$ cents if you choose B.

- Player $\mathbf{Z}$ will receive $\mathbf{1 0}$ cents if you choose $\mathbf{A}$.

- Player $\mathbf{Z}$ will receive $\mathbf{5 0}$ cents if you choose $\mathbf{B}$.

Put differently, since you are in GAME 1, according to whether you choose A or B. the payoffs for you and Player $Z$ can be described as follows:

\begin{tabular}{|l|l|c|}
\hline & \multicolumn{2}{|c|}{ GAME 1 } \\
\hline & $\begin{array}{l}\text { You Will } \\
\text { Receive }\end{array}$ & $\begin{array}{c}\text { Player } \mathbf{Z} \text { Will } \\
\text { Receive }\end{array}$ \\
\hline A & 60 cents & 10 cents \\
\hline B & 50 cents & 50 cents \\
\hline
\end{tabular}

Now, please make your decision in this game (by choosing A or B) given that:

- If you choose $\mathbf{A}$, you will receive 60 cents, and Player $Z$ will receive 10 cents.

- If you choose B, you will receive 50 cents, and Player $Z$ will receive 50 cents. 
Figure B.16: Hidden Information $\times$ Other/Other $\times$ Aligned State, After Revealing Player Z's Payoffs

You chose to Reveal Player Z's Payoffs. Note that you are in GAME 2 and thus:

- Player $\mathbf{Y}$ will receive 60 cents if you choose A.

- Player $\mathbf{Y}$ will receive $\mathbf{5 0}$ cents if you choose B.

- Player $\mathbf{Z}$ will receive $\mathbf{5 0}$ cents if you choose $\mathbf{A}$.

- Player $\mathbf{Z}$ will receive $\mathbf{1 0}$ cents if you choose B.

Put differently, since you are in GAME 2, according to whether you choose A or B, the payoffs for Player $Y$ and Player $Z$ can be described as follows:

\begin{tabular}{|c|c|c|}
\hline & \multicolumn{2}{|c|}{ GAME 2} \\
\hline & $\begin{array}{c}\text { Player } Y \text { Will } \\
\text { Receive }\end{array}$ & $\begin{array}{c}\text { Player } Z \text { Will } \\
\text { Receive }\end{array}$ \\
\hline A & 60 cents & 50 cents \\
\hline B & 50 cents & 10 cents \\
\hline
\end{tabular}

Now, please make your decision in this game (by choosing A or B) given that:

- If you choose A, Player $Y$ will receive 60 cents, and Player $Z$ will receive 50 cents.

- If you choose B, Player $Y$ will receive 50 cents, and Player $Z$ will receive 10 cents. 
Figure B.17: Hidden Information $\times$ Other/Other $\times$ Unaligned State, After Revealing Player Z's Payoffs

You chose to Reveal Player Z's payoffs. Note that you are in GAME 1 and thus:

- Player $\mathbf{Y}$ will receive $\mathbf{6 0}$ cents if you choose $\mathbf{A}$.

- Player $\mathbf{Y}$ will receive $\mathbf{5 0}$ cents if you choose B.

- Player $Z$ will receive $\mathbf{1 0}$ cents if you choose $\mathbf{A}$.

- Player $\mathbf{Z}$ will receive $\mathbf{5 0}$ cents if you choose $\mathbf{B}$.

Put differently, since you are in GAME 1, according to whether you choose A or B. the payoffs for Player $Y$ and Player $Z$ can be described as follows:

\begin{tabular}{|c|c|c|}
\hline & \multicolumn{2}{|c|}{ GAME 1 } \\
\hline & $\begin{array}{c}\text { Player } Y \text { Will } \\
\text { Receive }\end{array}$ & $\begin{array}{c}\text { Player } Z \text { Will } \\
\text { Receive }\end{array}$ \\
\hline A & 60 cents & 10 cents \\
\hline B & 50 cents & 50 cents \\
\hline
\end{tabular}

Now, please make your decision in this game (by choosing A or B) given that:

- If you choose A, Player $Y$ will receive 60 cents, and Player $Z$ will receive 10 cents.

- If you choose B, Player $Y$ will receive 50 cents, and Player $Z$ will receive 50 cents. 


\section{B.2 Experimental Instructions for Study 2}

Participants in Study 2 were randomly assigned to 1 of 16 conditions. The first set of 8 involved the same conditions as in Study 1, which we call the "Classic Payoffs" conditions that arise from (Hidden Information, Known Information $) \times($ Self/Other, Other/Other $) \times($ Unaligned state, Aligned state). The second set of 8 conditions involved new conditions, which we call "New Payoffs" that arise from (Hidden Information, Known Information) $\times($ Self/Other-New, Other/Other-New $) \times($ Aligned State 1, Aligned State 2). See Section B.1 for the conditions that were also included in Study 1. In what follows, we describe the 8 new conditions.

After consenting to participate in the study, participants are informed of the $\$ 0.50$ study completion fee and of the opportunity to earn an additional payment equivalent to Study 1 (as shown in Figure B.1). Participants are then provided with instructions about their decision and asked to answer comprehension questions. Figures B.18-B.23 show the instructions and comprehension questions for each of the respective conditions. 
Figure B.18: Known Information $\times$ Self/Other-New $\times$ Aligned State 1, Comprehension Questions

The game: You must choose A or B, which corresponds to payoffs for you and Player $Z$. Thus, the decision you make in this game will not influence payoffs for Player Y.

In particular:

- You will receive $\mathbf{5 0}$ cents if you choose $\mathbf{A}$.

- You will receive $\mathbf{5 0}$ cents if you choose $\mathbf{B}$.

- Player $\mathbf{Z}$ will receive $\mathbf{5 0}$ cents if you choose $\mathbf{A}$.

- Player $\mathbf{Z}$ will receive $\mathbf{1 0}$ cents if you choose $\mathbf{B}$.

Put differently, according to whether you choose A or B, the payoffs for you and Player Z can be described as follows:

\begin{tabular}{|l|l|c|}
\hline & $\begin{array}{l}\text { You Will } \\
\text { Receive }\end{array}$ & $\begin{array}{c}\text { Player } \mathbf{Z} \text { Will } \\
\text { Receive }\end{array}$ \\
\hline A & 50 cents & 50 cents \\
\hline B & 50 cents & 10 cents \\
\hline
\end{tabular}

Understanding Question: You will receive more money if. . .

you choose $A$.

you choose $B$.

None of the above. You will receive the same amount of money regardless of what you choose.

Understanding Question: Player Z will receive more money if. . .

you choose $\mathrm{A}$.

you choose B. 
Figure B.19: Known Information $\times$ Self/Other-New $\times$ Aligned State 2, Comprehension Questions

The game: You must choose A or B, which corresponds to payoffs for you and Player $Z$. Thus, the decision you make in this game will not influence payoffs for Player $\mathrm{Y}$.

In particular:

- You will receive $\mathbf{5 0}$ cents if you choose $\mathbf{A}$.

- You will receive $\mathbf{5 0}$ cents if you choose B.

- Player $\mathbf{Z}$ will receive $\mathbf{1 0}$ cents if you choose $\mathbf{A}$.

- Player $\mathbf{Z}$ will receive $\mathbf{5 0}$ cents if you choose $\mathbf{B}$.

Put differently, according to whether you choose A or B. the payoffs for you and Player Z can be described as follows:

\begin{tabular}{|l|l|c|}
\hline & $\begin{array}{l}\text { You Will } \\
\text { Receive }\end{array}$ & $\begin{array}{c}\text { Player } \mathbf{Z} \text { Will } \\
\text { Receive }\end{array}$ \\
\hline A & 50 cents & 10 cents \\
\hline B & 50 cents & 50 cents \\
\hline
\end{tabular}

Understanding Question: You will receive more money if. . .

you choose $A$.

you choose B.

None of the above. You will receive the same amount of money regardless of what you choose.

Understanding Question: Player Z will receive more money if. . .

you choose $A$.

you choose $B$. 
Figure B.20: Known Information $\times$ Other/Other-New $\times$ Aligned State 1, Comprehension Questions

The game: You must choose A or B, which corresponds to payoffs for Player $\mathrm{Y}$ and Player

$Z$. Thus, the decision you make in this game will not influence payoffs for you.

In particular:

- Player $\mathbf{Y}$ will receive $\mathbf{5 0}$ cents if you choose $\mathbf{A}$.

- Player $\mathbf{Y}$ will receive $\mathbf{5 0}$ cents if you choose $\mathbf{B}$.

- Player $\mathbf{Z}$ will receive $\mathbf{5 0}$ cents if you choose $\mathbf{A}$.

- Player $\mathbf{Z}$ will receive $\mathbf{1 0}$ cents if you choose $\mathbf{B}$.

Put differently, according to whether you choose A or B, the payoffs for Player $\mathrm{Y}$ and Player $Z$ can be described as follows:

\begin{tabular}{|c|c|c|}
\hline & $\begin{array}{c}\text { Player } \mathbf{Y} \text { Will } \\
\text { Receive }\end{array}$ & $\begin{array}{c}\text { Player } \mathbf{Z} \text { Will } \\
\text { Receive }\end{array}$ \\
\hline A & $\mathbf{5 0}$ cents & $\mathbf{5 0}$ cents \\
\hline B & $\mathbf{5 0}$ cents & 10 cents \\
\hline
\end{tabular}

Understanding Question: Player Y will receive more money if. . .

you choose $A$.

you choose $B$.

None of the above. Player $Y$ will receive the same amount of money regardless of what you choose.

Understanding Question: Player Z will receive more money if. . .

you choose $A$.

you choose $B$. 
Figure B.21: Known Information $\times$ Other/Other-New $\times$ Aligned State 2, Comprehension Questions

The game: You must choose A or B, which corresponds to payoffs for Player Y and Player $Z$. Thus, the decision you make in this game will not influence payoffs for you.

In particular:

- Player $\mathbf{Y}$ will receive $\mathbf{5 0}$ cents if you choose $\mathbf{A}$.

- Player $\mathbf{Y}$ will receive $\mathbf{5 0}$ cents if you choose B.

- Player $Z$ will receive $\mathbf{1 0}$ cents if you choose $\mathbf{A}$.

- Player $\mathbf{Z}$ will receive $\mathbf{5 0}$ cents if you choose $\mathbf{B}$.

Put differently, according to whether you choose A or B. the payoffs for Player $\mathrm{Y}$ and Player $Z$ can be described as follows:

\begin{tabular}{|l|c|c|}
\hline & $\begin{array}{c}\text { Player } Y \text { Will } \\
\text { Receive }\end{array}$ & $\begin{array}{c}\text { Player } \mathbf{Z} \text { Will } \\
\text { Receive }\end{array}$ \\
\hline A & 50 cents & 10 cents \\
\hline B & 50 cents & 50 cents \\
\hline
\end{tabular}

Understanding Question: Player Y will receive more money if. . .

you choose $\mathrm{A}$.

you choose $B$.

None of the above. Player $\mathrm{Y}$ will receive the same amount of money regardless of what you choose.

Understanding Question: Player Z will receive more money if. . .

you choose $A$.

you choose B. 
Figure B.22: Hidden Information $\times$ Self/Other-New, Comprehension Questions

The game: You must choose A or B, which corresponds to payoffs for you and Player Z. Thus, the decision you make in this game will not influence payoffs for Player $Y$.

There is a $50 \%$ chance that you are in GAME 1 and a $50 \%$ that you are in GAME 2.

Both games are the same except that Player Z's payoffs are flipped between the two games. In particular:

- You will receive $\mathbf{5 0}$ cents if you choose $\mathbf{A}$ in either game.

- You will receive $\mathbf{5 0}$ cents if you choose B in either game.

- Player $\mathbf{Z}$ will receive 10 cents if you choose $\mathbf{A}$ in GAME 1 or $\mathbf{B}$ in GAME 2.

- Player $\mathbf{Z}$ will receive $\mathbf{5 0}$ cents if you choose $\mathbf{B}$ in GAME 1 or $\mathbf{A}$ in GAME 2.

Put differently, according to whether you are in GAME 1 or GAME 2 and whether you choose $\mathrm{A}$ or $\mathrm{B}$, the payoffs for you and Player $\mathrm{Z}$ can be described as follows:

\begin{tabular}{|c|c|c|}
\hline & \multicolumn{2}{|c|}{ GAME 1 } \\
\cline { 2 - 3 } & $\begin{array}{l}\text { You Will } \\
\text { Receive }\end{array}$ & $\begin{array}{c}\text { Player Z Will } \\
\text { Receive }\end{array}$ \\
\hline A & 50 cents & 10 cents \\
\hline B & 50 cents & 50 cents \\
\hline
\end{tabular}

\begin{tabular}{|c|c|c|}
\hline & \multicolumn{2}{|c|}{ GAME 2 } \\
\hline & $\begin{array}{l}\text { You Will } \\
\text { Receive }\end{array}$ & $\begin{array}{c}\text { Player } \mathbf{Z} \text { Will } \\
\text { Receive }\end{array}$ \\
\hline A & 50 cents & 50 cents \\
\hline B & 50 cents & 10 cents \\
\hline
\end{tabular}

Understanding Question: You will receive more money if. . .

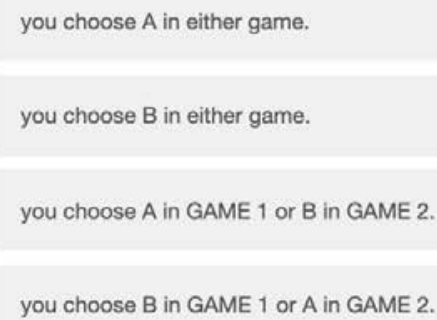

Understanding Question: Player Z will receive more money if. . .

you choose $\mathrm{A}$ in either game.

you choose $B$ in either game.

you choose $A$ in GAME 1 or B in GAME 2. 
Figure B.23: Hidden Information $\times$ Other/Other-New, Comprehension Questions

The game: You must choose $A$ or $B$, which corresponds to payoffs for Player $Y$ and Player $Z$. Thus, the decision you make in this game will not influence payoffs for you.

There is a $50 \%$ chance that you are in GAME 1 and a $50 \%$ that you are in GAME 2.

Both games are the same except that Player Z's payoffs are flipped between the two games. In particular:

- Player $\mathbf{Y}$ will receive $\mathbf{5 0}$ cents if you choose $\mathbf{A}$ in either game.

- Player $\mathbf{Y}$ will receive $\mathbf{5 0}$ cents if you choose $\mathbf{B}$ in either game.

- Player $\mathbf{Z}$ will receive 10 cents if you choose $\mathbf{A}$ in GAME 1 or $\mathbf{B}$ in GAME 2.

- Player $\mathbf{Z}$ will receive $\mathbf{5 0}$ cents if you choose $\mathbf{B}$ in GAME $\mathbf{1}$ or $\mathbf{A}$ in GAME 2.

Put differently, according to whether you are in GAME 1 or GAME 2 and whether you choose $\mathrm{A}$ or $\mathrm{B}$, the payoffs for Player $\mathrm{Y}$ and Player $\mathrm{Z}$ can be described as follows:

\begin{tabular}{|c|c|c|}
\hline & \multicolumn{2}{|c|}{ GAME 1 } \\
\hline & $\begin{array}{c}\text { Player } Y \text { Will } \\
\text { Receive }\end{array}$ & $\begin{array}{c}\text { Player } \mathbf{Z} \text { Will } \\
\text { Receive }\end{array}$ \\
\hline A & 50 cents & 10 cents \\
\hline B & 50 cents & 50 cents \\
\hline
\end{tabular}

\begin{tabular}{|c|c|c|}
\hline & \multicolumn{2}{|c|}{ GAME 2 } \\
\hline & $\begin{array}{c}\text { Player } Y \text { Will } \\
\text { Receive }\end{array}$ & $\begin{array}{c}\text { Player } Z \text { Will } \\
\text { Receive }\end{array}$ \\
\hline A & 50 cents & 50 cents \\
\hline B & 50 cents & 10 cents \\
\hline
\end{tabular}

Understanding Question: Player $\mathrm{Y}$ will receive more money if. . .

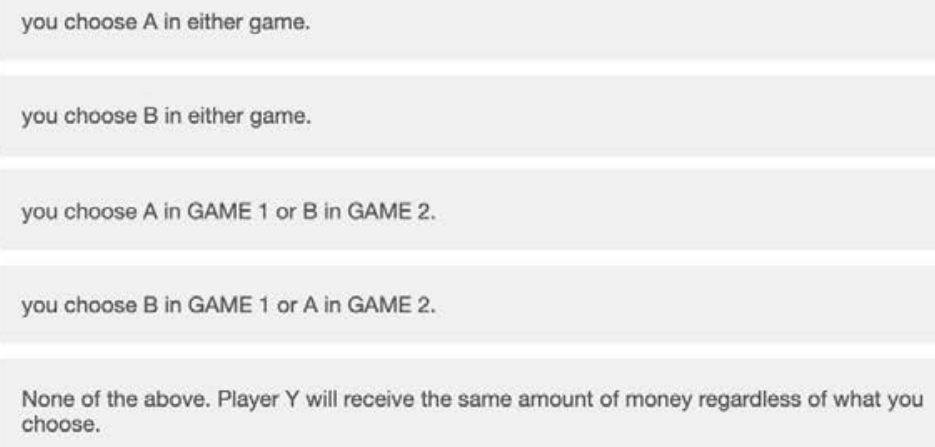

Understanding Question: Player $\mathbf{Z}$ will receive more money if. . .

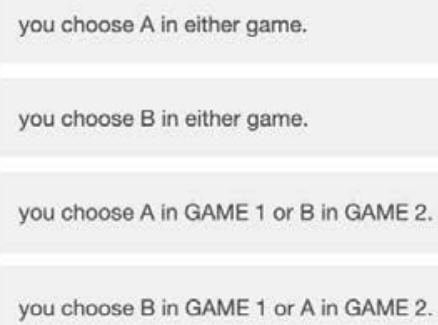


Participants are then reminded of the instructions and asked to make their decisions. Figures B.24-B.29 show the decision screens for each of the conditions. If participants in those conditions choose to Reveal Player Z's payoffs, the state is revealed on the next page and they are asked to make their decision, as shown below in Figures B.30-B.33.

Figure B.24: Known Information $\times$ Self/Other - New $\times$ Aligned State 1, Decision

The game: You must choose A or B, which corresponds to payoffs for you and Player Z. Thus, the decision you make in this game will not influence payoffs for Player $\mathrm{Y}$.

In particular:

- You will receive $\mathbf{5 0}$ cents if you choose $\mathbf{A}$.

- You will receive $\mathbf{5 0}$ cents if you choose B.

- Player $\mathbf{Z}$ will receive $\mathbf{5 0}$ cents if you choose $\mathbf{A}$.

- Player $\mathbf{Z}$ will receive $\mathbf{1 0}$ cents if you choose $\mathbf{B}$.

Put differently, according to whether you choose A or B, the payoffs for you and Player Z can be described as follows:

\begin{tabular}{|l|l|l|}
\hline & $\begin{array}{l}\text { You Will } \\
\text { Receive }\end{array}$ & $\begin{array}{c}\text { Player } \mathbf{Z} \text { Will } \\
\text { Receive }\end{array}$ \\
\hline A & 50 cents & 50 cents \\
\hline B & 50 cents & 10 cents \\
\hline
\end{tabular}

Now, please make your decision in this game (by choosing A or B) given that:

- If you choose $A$, you will receive 50 cents, and Player $Z$ will receive 50 cents.

- If you choose B, you will receive 50 cents, and Player $Z$ will receive 10 cents. 
Figure B.25: Known Information $\times$ Self/Other-New $\times$ Aligned State 2, Decision

The game: You must choose A or B, which corresponds to payoffs for you and Player Z. Thus, the decision you make in this game will not influence payoffs for Player $Y$.

In particular:

- You will receive $\mathbf{5 0}$ cents if you choose $\mathbf{A}$.

- You will receive $\mathbf{5 0}$ cents if you choose B.

- Player $Z$ will receive $\mathbf{1 0}$ cents if you choose $\mathbf{A}$.

- Player $\mathbf{Z}$ will receive $\mathbf{5 0}$ cents if you choose $\mathbf{B}$.

Put differently, according to whether you choose A or B. the payoffs for you and Player Z can be described as follows:

\begin{tabular}{|l|l|l|}
\hline & $\begin{array}{l}\text { You Will } \\
\text { Receive }\end{array}$ & $\begin{array}{c}\text { Player } \mathbf{Z} \text { Will } \\
\text { Receive }\end{array}$ \\
\hline A & $\mathbf{5 0}$ cents & 10 cents \\
\hline B & $\mathbf{5 0}$ cents & $\mathbf{5 0}$ cents \\
\hline
\end{tabular}

Now, please make your decision in this game (by choosing A or B) given that:

- If you choose $\mathbf{A}$, you will receive 50 cents, and Player $Z$ will receive 10 cents.

- If you choose B, you will receive 50 cents, and Player $Z$ will receive 50 cents. 
Figure B.26: Known Information $\times$ Other/Other-New $\times$ Aligned State 1 , Decision

The game: You must choose A or B, which corresponds to payoffs for Player $\mathrm{Y}$ and Player $Z$. Thus, the decision you make in this game will not influence payoffs for you.

In particular:

- Player $\mathbf{Y}$ will receive $\mathbf{5 0}$ cents if you choose $\mathbf{A}$.

- Player $\mathbf{Y}$ will receive $\mathbf{5 0}$ cents if you choose $\mathbf{B}$.

- Player $\mathbf{Z}$ will receive $\mathbf{5 0}$ cents if you choose $\mathbf{A}$.

- Player $\mathbf{Z}$ will receive $\mathbf{1 0}$ cents if you choose $\mathbf{B}$.

Put differently, according to whether you choose A or B, the payoffs for Player $\mathrm{Y}$ and Player $Z$ can be described as follows:

\begin{tabular}{|c|c|c|}
\hline & $\begin{array}{c}\text { Player } \mathbf{Y} \text { Will } \\
\text { Receive }\end{array}$ & $\begin{array}{c}\text { Player } \mathbf{Z} \text { Will } \\
\text { Receive }\end{array}$ \\
\hline A & $\mathbf{5 0}$ cents & $\mathbf{5 0}$ cents \\
\hline B & $\mathbf{5 0}$ cents & 10 cents \\
\hline
\end{tabular}

Now, please make your decision in this game (by choosing A or B) given that:

- If you choose A, Player $Y$ will receive 50 cents, and Player $Z$ will receive 50 cents.

- If you choose B, Player $Y$ will receive 50 cents, and Player $Z$ will receive 10 cents. 
Figure B.27: Known Information $\times$ Other/Other-New $\times$ Aligned State 2, Decision

The game: You must choose A or B, which corresponds to payoffs for Player $Y$ and Player $Z$. Thus, the decision you make in this game will not influence payoffs for you.

In particular:

- Player $\mathbf{Y}$ will receive $\mathbf{5 0}$ cents if you choose $\mathbf{A}$.

- Player $\mathbf{Y}$ will receive $\mathbf{5 0}$ cents if you choose $\mathbf{B}$.

- Player $Z$ will receive $\mathbf{1 0}$ cents if you choose $\mathbf{A}$.

- Player $\mathbf{Z}$ will receive $\mathbf{5 0}$ cents if you choose $\mathbf{B}$.

Put differently, according to whether you choose A or B. the payoffs for Player $\mathrm{Y}$ and Player $Z$ can be described as follows:

\begin{tabular}{|l|c|c|}
\hline & $\begin{array}{c}\text { Player } \mathbf{Y} \text { Will } \\
\text { Receive }\end{array}$ & $\begin{array}{c}\text { Player } \mathbf{Z} \text { Will } \\
\text { Receive }\end{array}$ \\
\hline A & $\mathbf{5 0}$ cents & 10 cents \\
\hline B & $\mathbf{5 0}$ cents & $\mathbf{5 0}$ cents \\
\hline
\end{tabular}

Now, please make your decision in this game (by choosing A or B) given that:

- If you choose A, Player $Y$ will receive 50 cents, and Player $Z$ will receive 10 cents.

- If you choose B, Player $Y$ will receive 50 cents, and Player $Z$ will receive 50 cents. 
Figure B.28: Hidden Information $\times$ Self/Other-New, Decision

The game: You must choose A or B, which corresponds to payoffs for you and Player Z. Thus, the decision you make in this game will not influence payoffs for Player $Y$.

There is a $50 \%$ chance that you are in GAME 1 and a $50 \%$ that you are in GAME 2.

Both games are the same except that Player Z's payoffs are flipped between the two games. In particular:

- You will receive $\mathbf{5 0}$ cents if you choose $\mathbf{A}$ in either game.

- You will receive $\mathbf{5 0}$ cents if you choose $\mathbf{B}$ in either game.

- Player $\mathbf{Z}$ will receive 10 cents if you choose $\mathbf{A}$ in GAME 1 or $\mathbf{B}$ in GAME 2.

- Player $\mathbf{Z}$ will receive $\mathbf{5 0}$ cents if you choose B in GAME 1 or A in GAME 2.

Put differently, according to whether you are in GAME 1 or GAME 2 and whether you choose A or B, the payoffs for you and Player $\mathrm{Z}$ can be described as follows:

\begin{tabular}{|l|l|c|}
\hline & \multicolumn{2}{|c|}{ GAME 1 } \\
\hline & $\begin{array}{l}\text { You Will } \\
\text { Receive }\end{array}$ & $\begin{array}{c}\text { Player } \mathbf{Z} \text { Will } \\
\text { Receive }\end{array}$ \\
\hline A & 50 cents & 10 cents \\
\hline B & 50 cents & 50 cents \\
\hline
\end{tabular}

\begin{tabular}{|c|c|c|}
\hline & \multicolumn{2}{|c|}{ GAME 2 } \\
\hline & $\begin{array}{l}\text { You Will } \\
\text { Receive }\end{array}$ & $\begin{array}{c}\text { Player } \mathbf{Z} \text { Will } \\
\text { Receive }\end{array}$ \\
\hline A & 50 cents & 50 cents \\
\hline B & 50 cents & 10 cents \\
\hline
\end{tabular}

Now, please make your decision in this game (by choosing A or B) or instead indicate that you would like to make your decision after being informed of which game you are in (by choosing Reveal Player Z's Payoffs) given that:

- If you choose $\mathbf{A}$, you will receive $\mathbf{5 0}$ cents regardless of which game you are in, and Player $Z$ will receive 10 cents if you are in GAME 1 or 50 cents if you are in GAME 2.

- If you choose $\mathbf{B}$, you will receive $\mathbf{5 0}$ cents regardless of which game you are in, and Player $Z$ will receive 50 cents if you are in GAME 1 or 10 cents if you are in GAME 2.

- If you choose Reveal Player Z's Payoffs, information on the next page will reveal whether you are in GAME 1 or GAME 2 and thus will reveal the exact payoffs that Player $\mathrm{Z}$ will receive if you choose $\mathrm{A}$ or $\mathrm{B}$. After this information is revealed, you will choose between $\mathrm{A}$ and $\mathrm{B}$. 
Figure B.29: Hidden Information $\times$ Other/Other-New, Decision

The game: You must choose $\mathrm{A}$ or $\mathrm{B}$, which corresponds to payoffs for Player $\mathrm{Y}$ and Player $Z$. Thus, the decision you make in this game will not influence payoffs for you.

There is a $50 \%$ chance that you are in GAME 1 and a $50 \%$ that you are in GAME 2.

Both games are the same except that Player Z's payoffs are flipped between the two games. In particular:

- Player $\mathbf{Y}$ will receive $\mathbf{5 0}$ cents if you choose $\mathbf{A}$ in either game.

- Player $\mathbf{Y}$ will receive $\mathbf{5 0}$ cents if you choose $\mathbf{B}$ in either game.

- Player $\mathbf{Z}$ will receive 10 cents if you choose $\mathbf{A}$ in GAME 1 or $\mathbf{B}$ in GAME 2.

- Player $\mathbf{Z}$ will receive $\mathbf{5 0}$ cents if you choose $\mathbf{B}$ in GAME $\mathbf{1}$ or $\mathbf{A}$ in GAME 2.

Put differently, according to whether you are in GAME 1 or GAME 2 and whether you choose $A$ or $B$, the payoffs for Player $Y$ and Player $Z$ can be described as follows:

\begin{tabular}{|c|c|c|}
\hline & \multicolumn{2}{|c|}{ GAME 1} \\
\hline & $\begin{array}{c}\text { Player } \mathrm{Y} \text { Will } \\
\text { Receive }\end{array}$ & $\begin{array}{c}\text { Player } \mathbf{Z} \text { Will } \\
\text { Receive }\end{array}$ \\
\hline A & 50 cents & 10 cents \\
\hline B & 50 cents & 50 cents \\
\hline
\end{tabular}

\begin{tabular}{|c|c|c|}
\hline & \multicolumn{2}{|c|}{ GAME 2 } \\
\hline & $\begin{array}{c}\text { Player } Y \text { Will } \\
\text { Receive }\end{array}$ & $\begin{array}{c}\text { Player } Z \text { Will } \\
\text { Receive }\end{array}$ \\
\hline A & 50 cents & 50 cents \\
\hline B & 50 cents & 10 cents \\
\hline
\end{tabular}

Now, please make your decision in this game (by choosing A or B) or instead indicate that you would like to make your decision after being informed of which game you are in (by choosing Reveal Player Z's Payoffs) given that:

- If you choose A, Player $Y$ will receive 50 cents regardless of which game you are in, and Player $Z$ will receive 10 cents if you are in GAME 1 or 50 cents if you are in GAME 2.

- If you choose $B, P l a y e r ~ Y$ will receive 50 cents regardless of which game you are in, and Player $Z$ will receive 50 cents if you are in GAME 1 or 10 cents if you are in GAME 2.

- If you choose Reveal Player Z's Payoffs, information on the next page will reveal whether you are in GAME 1 or GAME 2 and thus will reveal the exact payoffs that Player $Z$ will receive if you choose $A$ or $B$. After this information is revealed, you will choose between A and B. 
Figure B.30: Hidden Information $\times$ Self/Other-New $\times$ Aligned State 1, After Revealing Player Z's Payoffs

You chose to Reveal Player Z's Payoffs. Note that you are in GAME 2 and thus:

- You will receive $\mathbf{5 0}$ cents if you choose $\mathbf{A}$.

- You will receive $\mathbf{5 0}$ cents if you choose B.

- Player $\mathbf{Z}$ will receive $\mathbf{5 0}$ cents if you choose $\mathbf{A}$.

- Player $\mathbf{Z}$ will receive $\mathbf{1 0}$ cents if you choose B.

Put differently, since you are in GAME 2, according to whether you choose A or B, the payoffs for you and Player $Z$ can be described as follows:

\begin{tabular}{|l|l|c|}
\hline & \multicolumn{2}{|c|}{ GAME 2} \\
\hline & $\begin{array}{l}\text { You Will } \\
\text { Receive }\end{array}$ & $\begin{array}{c}\text { Player Z Will } \\
\text { Receive }\end{array}$ \\
\hline A & 50 cents & 50 cents \\
\hline B & 50 cents & 10 cents \\
\hline
\end{tabular}

Now, please make your decision in this game (by choosing A or B) given that:

- If you choose $A$, you will receive 50 cents, and Player $Z$ will receive 50 cents.

- If you choose B, you will receive 50 cents, and Player $Z$ will receive 10 cents. 
Figure B.31: Hidden Information $\times$ Self/Other-New $\times$ Aligned State 2, After Revealing Player Z's Payoffs

You chose to Reveal Player Z's payoffs. Note that you are in GAME 1 and thus:

- You will receive $\mathbf{5 0}$ cents if you choose $\mathbf{A}$.

- You will receive $\mathbf{5 0}$ cents if you choose B.

- Player $\mathbf{Z}$ will receive $\mathbf{1 0}$ cents if you choose $\mathbf{A}$.

- Player $\mathbf{Z}$ will receive $\mathbf{5 0}$ cents if you choose $\mathbf{B}$.

Put differently, since you are in GAME 1, according to whether you choose A or B. the payoffs for you and Player $Z$ can be described as follows:

\begin{tabular}{|l|l|c|}
\hline & \multicolumn{2}{|c|}{ GAME 1 } \\
\hline & $\begin{array}{l}\text { You Will } \\
\text { Receive }\end{array}$ & $\begin{array}{c}\text { Player Z Will } \\
\text { Receive }\end{array}$ \\
\hline A & 50 cents & 10 cents \\
\hline B & 50 cents & 50 cents \\
\hline
\end{tabular}

Now, please make your decision in this game (by choosing A or B) given that:

- If you choose $A$, you will receive 50 cents, and Player $Z$ will receive 10 cents.

- If you choose B, you will receive 50 cents, and Player $Z$ will receive 50 cents. 
Figure B.32: Hidden Information $\times$ Other/Other-New $\times$ Aligned State 1 , After Revealing Player Z's Payoffs

You chose to Reveal Player Z's Payoffs. Note that you are in GAME 2 and thus:

- Player $\mathbf{Y}$ will receive $\mathbf{5 0}$ cents if you choose $\mathbf{A}$.

- Player $\mathbf{Y}$ will receive $\mathbf{5 0}$ cents if you choose $\mathbf{B}$.

- Player $\mathbf{Z}$ will receive $\mathbf{5 0}$ cents if you choose $\mathbf{A}$.

- Player $\mathbf{Z}$ will receive $\mathbf{1 0}$ cents if you choose B.

Put differently, since you are in GAME 2, according to whether you choose A or B, the payoffs for Player $Y$ and Player $Z$ can be described as follows:

\begin{tabular}{|c|c|c|}
\hline & \multicolumn{2}{|c|}{ GAME 2 } \\
\hline & $\begin{array}{c}\text { Player } \text { Y Will } \\
\text { Receive }\end{array}$ & $\begin{array}{c}\text { Player Z Will } \\
\text { Receive }\end{array}$ \\
\hline A & 50 cents & 50 cents \\
\hline B & 50 cents & 10 cents \\
\hline
\end{tabular}

Now, please make your decision in this game (by choosing A or B) given that:

- If you choose A, Player $Y$ will receive 50 cents, and Player $Z$ will receive 50 cents.

- If you choose B, Player $Y$ will receive 50 cents, and Player $Z$ will receive 10 cents. 
Figure B.33: Hidden Information $\times$ Other/Other-New $\times$ Aligned State 2, After Revealing Player Z's Payoffs

You chose to Reveal Player Z's payoffs. Note that you are in GAME 1 and thus:

- Player $\mathbf{Y}$ will receive $\mathbf{5 0}$ cents if you choose $\mathbf{A}$.

- Player $\mathbf{Y}$ will receive $\mathbf{5 0}$ cents if you choose $\mathbf{B}$.

- Player $\mathbf{Z}$ will receive $\mathbf{1 0}$ cents if you choose $\mathbf{A}$.

- Player $\mathbf{Z}$ will receive $\mathbf{5 0}$ cents if you choose $\mathbf{B}$.

Put differently, since you are in GAME 1, according to whether you choose A or B. the payoffs for Player $\mathrm{Y}$ and Player $\mathrm{Z}$ can be described as follows:

\begin{tabular}{|c|c|c|}
\hline & \multicolumn{2}{|c|}{ GAME 1 } \\
\hline & $\begin{array}{c}\text { Player } \mathbf{Y} \text { Will } \\
\text { Receive }\end{array}$ & $\begin{array}{c}\text { Player } \mathbf{Z} \text { Will } \\
\text { Receive }\end{array}$ \\
\hline A & $\mathbf{5 0}$ cents & 10 cents \\
\hline B & $\mathbf{5 0}$ cents & $\mathbf{5 0}$ cents \\
\hline
\end{tabular}

Now, please make your decision in this game (by choosing A or B) given that:

- If you choose A, Player $Y$ will receive 50 cents, and Player $Z$ will receive 10 cents.

- If you choose B, Player $Y$ will receive 50 cents, and Player $Z$ will receive 50 cents. 


\section{B.3 Experimental Instructions for Study 3}

Participants in Study 3 are randomly assigned to 1 of 20 conditions. The first set of 16 conditions were exactly the same as the 16 conditions in Study 2. The additional 4 conditions are new conditions, which we call "New Payoffs with Active Choice" that arise from (Hidden Information $) \times($ Self/Other-Active, Other/Other-Active $) \times($ Aligned State 1, Aligned State 2). See Sections B.1 and B.2 to learn more about the first 16 conditions included in Study 3. In what follows, we describe the 4 new conditions.

After consenting to participate in the study, subjects are informed of the $\$ 0.50$ study completion fee and of the opportunity to earn an additional payment equivalent to Study 1 and 2 (as shown in Figure B.1). Participants are then provided with instructions about their decision and asked to answer comprehension questions. Figures B.34-B.35 show the instructions and comprehension questions for each of the new conditions. 
Figure B.34: Hidden Information $\times$ Self/Other-Active, Comprehension Questions

The game: You must choose A or B, which corresponds to payoffs for you and Player Z.

Thus, the decision you make in this game will not influence payoffs for Player $\mathrm{Y}$.

There is a 50\% chance that you are in GAME 1 and a 50\% that you are in GAME 2.

Both games are the same except that Player Z's payoffs are flipped between the two games. In particular:

- You will receive $\mathbf{5 0}$ cents if you choose $\mathbf{A}$ in either game.

- You will receive $\mathbf{5 0}$ cents if you choose B in either game.

- Player $Z$ will receive $\mathbf{1 0}$ cents if you choose $A$ in GAME 1 or B in GAME 2.

- Player $\mathbf{Z}$ will receive $\mathbf{5 0}$ cents if you choose $\mathbf{B}$ in GAME $\mathbf{1}$ or $\mathbf{A}$ in GAME 2.

Put differently, according to whether you are in GAME 1 or GAME 2 and whether you choose $A$ or $B$, the payoffs for you and Player $Z$ can be described as follows:

\begin{tabular}{|l|l|c|}
\hline & \multicolumn{2}{|c|}{ GAME 1 } \\
\hline $\begin{array}{l}\text { You Will } \\
\text { Receive }\end{array}$ & $\begin{array}{c}\text { Player Z Will } \\
\text { Receive }\end{array}$ \\
\hline A & 50 cents & 10 cents \\
\hline B & 50 cents & 50 cents \\
\hline
\end{tabular}

\begin{tabular}{|l|l|c|}
\hline & \multicolumn{2}{|c|}{ GAME 2} \\
\hline & $\begin{array}{l}\text { You Will } \\
\text { Receive }\end{array}$ & $\begin{array}{c}\text { Player } \mathbf{Z} \text { Will } \\
\text { Receive }\end{array}$ \\
\hline A & 50 cents & 50 cents \\
\hline B & 50 cents & 10 cents \\
\hline
\end{tabular}

Understanding Question: You will receive more money if. . .

you choose $A$ in either game.

you choose $B$ in either game.

you choose $\mathrm{A}$ in GAME 1 or $\mathrm{B}$ in GAME 2.

you choose B in GAME 1 or A in GAME 2.

None of the above. You will receive the same amount of money regardless of what you choose.

Understanding Question: Player Z will receive more money if. . .

you choose $\mathrm{A}$ in either game.

you choose $B$ in either game.

you choose $A$ in GAME 1 or $B$ in GAME 2.

you choose $B$ in GAME 1 or A in GAME 2. 
Figure B.35: Hidden Information $\times$ Other/Other-Active, Comprehension Questions

The game: You must choose $A$ or $B$, which corresponds to payoffs for Player $Y$ and Player $Z$. Thus, the decision you make in this game will not influence payoffs for you.

There is a $50 \%$ chance that you are in GAME 1 and a $50 \%$ that you are in GAME 2.

Both games are the same except that Player Z's payoffs are flipped between the two games. In particular:

- Player $\mathbf{Y}$ will receive $\mathbf{5 0}$ cents if you choose $\mathbf{A}$ in either game.

- Player Y will receive $\mathbf{5 0}$ cents if you choose B in either game.

- Player $\mathbf{Z}$ will receive 10 cents if you choose $\mathbf{A}$ in GAME 1 or B in GAME 2.

- Player $\mathbf{Z}$ will receive $\mathbf{5 0}$ cents if you choose B in GAME 1 or A in GAME 2.

Put differently, according to whether you are in GAME 1 or GAME 2 and whether you choose $A$ or $B$, the payoffs for Player $Y$ and Player $Z$ can be described as follows:

\begin{tabular}{|c|c|c|}
\hline & \multicolumn{2}{|c|}{ GAME 1 } \\
\hline & $\begin{array}{c}\text { Player } Y \text { Will } \\
\text { Receive }\end{array}$ & $\begin{array}{c}\text { Player Z Will } \\
\text { Receive }\end{array}$ \\
\hline A & 50 cents & 10 cents \\
\hline B & 50 cents & 50 cents \\
\hline
\end{tabular}

\begin{tabular}{|c|c|c|}
\hline & \multicolumn{2}{|c|}{ GAME 2} \\
\hline & $\begin{array}{c}\text { Player } \text { Y Will } \\
\text { Receive }\end{array}$ & $\begin{array}{c}\text { Player Z Will } \\
\text { Receive }\end{array}$ \\
\hline A & 50 cents & 50 cents \\
\hline B & 50 cents & 10 cents \\
\hline
\end{tabular}

Understanding Question: Player $Y$ will receive more money if. . .

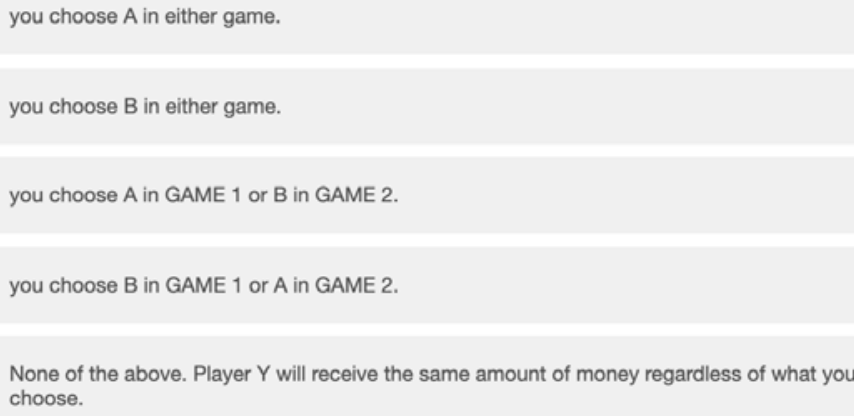

Understanding Question: Player Z will receive more money if. . .

you choose $\mathrm{A}$ in either game.

you choose B in either game.

you choose A in GAME 1 or B in GAME 2.

you choose B in GAME 1 or A in GAME 2. 
Participants are then reminded of the instructions and asked to make their decisions. Figures B.36-B.37 show the first decision screen for each of the new conditions. If participants in those conditions choose to Reveal Player Z's payoffs, the state is revealed on the next page and they are asked to make their decision, as shown below in Figures B.38-B.41. If participants choose not to Reveal Player Z's payoffs, they are instead asked to make a decision without learning their state, as shown below in Figures B.42-B.43.

Figure B.36: Hidden Information × Self/Other-Active, Revelation Decision

The game: You must choose A or B, which corresponds to payoffs for you and Player Z.

Thus, the decision you make in this game will not influence payoffs for Player $\mathrm{Y}$.

There is a $50 \%$ chance that you are in GAME 1 and a $50 \%$ that you are in GAME 2.

Both games are the same except that Player Z's payoffs are flipped between the two games. In particular:

- You will receive $\mathbf{5 0}$ cents if you choose $\mathbf{A}$ in either game.

- You will receive $\mathbf{5 0}$ cents if you choose $\mathbf{B}$ in either game.

- Player $\mathbf{Z}$ will receive $\mathbf{1 0}$ cents if you choose $\mathbf{A}$ in GAME 1 or B in GAME 2.

- Player $\mathbf{Z}$ will receive $\mathbf{5 0}$ cents if you choose $\mathbf{B}$ in GAME 1 or $\mathbf{A}$ in GAME 2.

Put differently, according to whether you are in GAME 1 or GAME 2 and whether you choose $A$ or $B$, the payoffs for you and Player $Z$ can be described as follows:

\begin{tabular}{|l|l|c|}
\hline & \multicolumn{2}{|c|}{ GAME 1 } \\
\hline $\begin{array}{l}\text { You Will } \\
\text { Receive }\end{array}$ & $\begin{array}{c}\text { Player } Z \text { Will } \\
\text { Receive }\end{array}$ \\
\hline A & 50 cents & 10 cents \\
\hline B & 50 cents & 50 cents \\
\hline
\end{tabular}

\begin{tabular}{|l|l|c|}
\hline & \multicolumn{2}{|c|}{ GAME 2} \\
\hline & $\begin{array}{l}\text { You Will } \\
\text { Receive }\end{array}$ & $\begin{array}{c}\text { Player } \mathbf{Z} \text { Will } \\
\text { Receive }\end{array}$ \\
\hline A & $\mathbf{5 0}$ cents & $\mathbf{5 0}$ cents \\
\hline B & $\mathbf{5 0}$ cents & 10 cents \\
\hline
\end{tabular}

To help you make your decision in this game on the next screen, would you like to Reveal Player Z's Payoffs so that information on the next screen reveals whether you are in Game 1 or Game 2? 
Figure B.37: Hidden Information $\times$ Other/Other-Active, Revelation Decision

The game: You must choose $\mathrm{A}$ or $\mathrm{B}$, which corresponds to payoffs for Player $\mathrm{Y}$ and Player Z. Thus, the decision you make in this game will not influence payoffs for you.

There is a $50 \%$ chance that you are in GAME 1 and a $50 \%$ that you are in GAME 2 .

Both games are the same except that Player Z's payoffs are flipped between the two games. In particular:

- Player $\mathbf{Y}$ will receive $\mathbf{5 0}$ cents if you choose $\mathbf{A}$ in either game.

- Player $\mathbf{Y}$ will receive $\mathbf{5 0}$ cents if you choose $\mathbf{B}$ in either game.

- Player $\mathbf{Z}$ will receive $\mathbf{1 0}$ cents if you choose $\mathbf{A}$ in GAME 1 or B in GAME 2.

- Player $\mathbf{Z}$ will receive $\mathbf{5 0}$ cents if you choose B in GAME 1 or A in GAME 2.

Put differently, according to whether you are in GAME 1 or GAME 2 and whether you choose $A$ or $B$, the payoffs for Player $Y$ and Player $Z$ can be described as follows:

\begin{tabular}{|c|c|c|}
\hline & \multicolumn{2}{|c|}{ GAME 1 } \\
\hline & $\begin{array}{c}\text { Player } Y \text { Will } \\
\text { Receive }\end{array}$ & $\begin{array}{c}\text { Player } Z \text { Will } \\
\text { Receive }\end{array}$ \\
\hline A & 50 cents & 10 cents \\
\hline B & 50 cents & 50 cents \\
\hline
\end{tabular}

\begin{tabular}{|c|c|c|}
\hline & \multicolumn{2}{|c|}{ GAME 2 } \\
\hline & $\begin{array}{c}\text { Player } Y \text { Will } \\
\text { Receive }\end{array}$ & $\begin{array}{c}\text { Player Z Will } \\
\text { Receive }\end{array}$ \\
\hline A & 50 cents & 50 cents \\
\hline B & 50 cents & 10 cents \\
\hline
\end{tabular}

To help you make your decision in this game on the next screen, would you like to Reveal Player Z's Payoffs so that information on the next screen reveals whether you are in Game 1 or Game 2? 
Figure B.38: Hidden Information $\times$ Self/Other-Active $\times$ Aligned State 1, After Choosing to Reveal Player Z's Payoffs

You chose Reveal Player Z's Payoffs. Note that you are in GAME 2 and thus:

- You will receive $\mathbf{5 0}$ cents if you choose $\mathbf{A}$.

- You will receive $\mathbf{5 0}$ cents if you choose B.

- Player $\mathbf{Z}$ will receive $\mathbf{5 0}$ cents if you choose $\mathbf{A}$.

- Player $\mathbf{Z}$ will receive $\mathbf{1 0}$ cents if you choose B.

Put differently, since you are in GAME 2, according to whether you choose A or B, the payoffs for you and Player $Z$ can be described as follows:

\begin{tabular}{|l|l|c|}
\hline & \multicolumn{2}{|c|}{ GAME 2} \\
\hline & $\begin{array}{l}\text { You Will } \\
\text { Receive }\end{array}$ & $\begin{array}{c}\text { Player } \mathbf{Z} \text { Will } \\
\text { Receive }\end{array}$ \\
\hline A & $\mathbf{5 0 ~ c e n t s ~}$ & $\mathbf{5 0}$ cents \\
\hline B & $\mathbf{5 0 ~ c e n t s ~}$ & 10 cents \\
\hline
\end{tabular}

Now, please make your decision in this game (by choosing A or B) given that:

- If you choose A, you will receive 50 cents, and Player $Z$ will receive 50 cents.

- If you choose B, you will receive 50 cents, and Player $Z$ will receive 10 cents. 
Figure B.39: Hidden Information $\times$ Self/Other-Active $\times$ Aligned State 2, After Choosing to Reveal Player Z's Payoffs

You chose Reveal Player Z's Payoffs. Note that you are in GAME 1 and thus:

- You will receive $\mathbf{5 0}$ cents if you choose A.

- You will receive $\mathbf{5 0}$ cents if you choose B.

- Player $\mathbf{Z}$ will receive $\mathbf{1 0}$ cents if you choose $\mathbf{A}$.

- Player $\mathbf{Z}$ will receive $\mathbf{5 0}$ cents if you choose B.

Put differently, since you are in GAME 1, according to whether you choose A or B. the payoffs for you and Player $Z$ can be described as follows:

\begin{tabular}{|c|c|c|}
\hline & \multicolumn{2}{|c|}{ GAME 1 } \\
\hline $\begin{array}{l}\text { You Will } \\
\text { Receive }\end{array}$ & $\begin{array}{c}\text { Player } \mathbf{Z} \text { Will } \\
\text { Receive }\end{array}$ \\
\hline A & $\mathbf{5 0}$ cents & $\mathbf{1 0}$ cents \\
\hline B & $\mathbf{5 0}$ cents & 50 cents \\
\hline
\end{tabular}

Now, please make your decision in this game (by choosing A or B) given that:

- If you choose $\mathbf{A}$, you will receive 50 cents, and Player $Z$ will receive 10 cents.

- If you choose B, you will receive 50 cents, and Player $Z$ will receive 50 cents. 
Figure B.40: Hidden Information $\times$ Other/Other-Active $\times$ Aligned State 1 , After Choosing to Reveal Player Z's Payoffs

You chose Reveal Player Z's Payoffs. Note that you are in GAME 2 and thus:

- Player $\mathbf{Y}$ will receive $\mathbf{5 0}$ cents if you choose $\mathbf{A}$.

- Player Y will receive $\mathbf{5 0}$ cents if you choose B.

- Player $\mathbf{Z}$ will receive $\mathbf{5 0}$ cents if you choose $\mathbf{A}$.

- Player $\mathbf{Z}$ will receive $\mathbf{1 0}$ cents if you choose $\mathbf{B}$.

Put differently, since you are in GAME 2, according to whether you choose A or B, the payoffs for Player $Y$ and Player $Z$ can be described as follows:

\begin{tabular}{|c|c|c|}
\hline & \multicolumn{2}{|c|}{ GAME 2} \\
\hline & $\begin{array}{c}\text { Player } Y \text { Will } \\
\text { Receive }\end{array}$ & $\begin{array}{c}\text { Player } Z \text { Will } \\
\text { Receive }\end{array}$ \\
\hline A & 50 cents & 50 cents \\
\hline B & 50 cents & 10 cents \\
\hline
\end{tabular}

Now, please make your decision in this game (by choosing A or B) given that:

- If you choose A, Player $Y$ will receive 50 cents, and Player $Z$ will receive 50 cents.

- If you choose B, Player $Y$ will receive 50 cents, and Player $Z$ will receive 10 cents. 
Figure B.41: Hidden Information $\times$ Other/Other-Active $\times$ Aligned State 2, After Choosing to Reveal Player Z's Payoffs

You chose Reveal Player Z's Payoffs. Note that you are in GAME 1 and thus:

- Player $\mathbf{Y}$ will receive $\mathbf{5 0}$ cents if you choose $\mathbf{A}$.

- Player $\mathbf{Y}$ will receive $\mathbf{5 0}$ cents if you choose $\mathbf{B}$.

- Player $Z$ will receive 10 cents if you choose $\mathbf{A}$.

- Player $\mathbf{Z}$ will receive $\mathbf{5 0}$ cents if you choose $\mathbf{B}$.

Put differently, since you are in GAME 1, according to whether you choose A or B. the payoffs for Player $Y$ and Player $Z$ can be described as follows:

\begin{tabular}{|c|c|c|}
\hline & \multicolumn{2}{|c|}{ GAME 1 } \\
\hline & $\begin{array}{c}\text { Player } \text { Y Will } \\
\text { Receive }\end{array}$ & $\begin{array}{c}\text { Player } \mathbf{Z} \text { Will } \\
\text { Receive }\end{array}$ \\
\hline A & $\mathbf{5 0}$ cents & 10 cents \\
\hline B & 50 cents & 50 cents \\
\hline
\end{tabular}

Now, please make your decision in this game (by choosing A or B) given that:

- If you choose $A$, Player $Y$ will receive 50 cents, and Player $Z$ will receive 10 cents.

- If you choose B, Player $Y$ will receive 50 cents, and Player $Z$ will receive 50 cents. 
Figure B.42: Hidden Information $\times$ Self/Other-Active, After Choosing Not to Reveal Player Z's Payoffs

You chose DO NOT Reveal Player Z's Payoffs. Thus, recall the previous information you received about the game:

The game: You must choose A or B, which corresponds to payoffs for you and Player Z. Thus, the decision you make in this game will not influence payoffs for Player $\mathrm{Y}$.

There is a $50 \%$ chance that you are in GAME 1 and a $50 \%$ that you are in GAME 2.

Both games are the same except that Player Z's payoffs are flipped between the two games. In particular:

- You will receive $\mathbf{5 0}$ cents if you choose $\mathbf{A}$ in either game.

- You will receive $\mathbf{5 0}$ cents if you choose $\mathbf{B}$ in either game.

- Player $Z$ will receive 10 cents if you choose $A$ in GAME 1 or B in GAME 2.

- Player $\mathbf{Z}$ will receive $\mathbf{5 0}$ cents if you choose B in GAME 1 or $\mathbf{A}$ in GAME 2.

Put differently, according to whether you are in GAME 1 or GAME 2 and whether you choose A or B, the payoffs for you and Player $Z$ can be described as follows:

\begin{tabular}{|c|c|c|}
\hline & \multicolumn{2}{|c|}{ GAME 1 } \\
\hline & $\begin{array}{l}\text { You Will } \\
\text { Receive }\end{array}$ & $\begin{array}{c}\text { Player } \mathbf{Z} \text { Will } \\
\text { Receive }\end{array}$ \\
\hline A & $\mathbf{5 0}$ cents & $\mathbf{1 0}$ cents \\
\hline B & 50 cents & 50 cents \\
\hline
\end{tabular}

\begin{tabular}{|l|l|c|}
\hline & \multicolumn{2}{|c|}{ GAME 2} \\
\hline & $\begin{array}{l}\text { You Will } \\
\text { Receive }\end{array}$ & $\begin{array}{c}\text { Player } \mathbf{Z} \text { Will } \\
\text { Receive }\end{array}$ \\
\hline A & $\mathbf{5 0}$ cents & $\mathbf{5 0}$ cents \\
\hline B & 50 cents & 10 cents \\
\hline
\end{tabular}

Now, please make your decision in this game (by choosing A or B) given that:

- If you choose A, you will receive 50 cents regardless of which game you are in, and Player $Z$ will receive 10 cents if you are in GAME 1 or 50 cents if you are in GAME 2.

- If you choose B, you will receive 50 cents regardless of which game you are in, and Player $Z$ will receive 50 cents if you are in GAME 1 or 10 cents if you are in GAME 2. 
Figure B.43: Hidden Information $\times$ Other/Other-Active, After Choosing Not to Reveal Player Z's Payoffs

You chose DO NOT Reveal Player Z's Payoffs. Thus, recall the previous information you received about the game:

The game: You must choose $A$ or $B$, which corresponds to payoffs for Player $\mathrm{Y}$ and Player Z. Thus, the decision you make in this game will not influence payoffs for you.

There is a $50 \%$ chance that you are in GAME 1 and a $50 \%$ that you are in GAME 2.

Both games are the same except that Player Z's payoffs are flipped between the two games. In particular:

- Player $\mathbf{Y}$ will receive $\mathbf{5 0}$ cents if you choose $\mathbf{A}$ in either game.

- Player $\mathbf{Y}$ will receive $\mathbf{5 0}$ cents if you choose $\mathbf{B}$ in either game.

- Player $Z$ will receive 10 cents if you choose $A$ in GAME 1 or $B$ in GAME 2.

- Player $\mathbf{Z}$ will receive $\mathbf{5 0}$ cents if you choose B in GAME $\mathbf{1}$ or $\mathbf{A}$ in GAME 2.

Put differently, according to whether you are in GAME 1 or GAME 2 and whether you choose $A$ or $B$, the payoffs for Player $Y$ and Player $Z$ can be described as follows:

\begin{tabular}{|c|c|c|}
\hline & \multicolumn{2}{|c|}{ GAME 1 } \\
\hline & $\begin{array}{c}\text { Player } Y \text { Will } \\
\text { Receive }\end{array}$ & $\begin{array}{c}\text { Player } Z \text { Will } \\
\text { Receive }\end{array}$ \\
\hline A & 50 cents & 10 cents \\
\hline B & 50 cents & 50 cents \\
\hline
\end{tabular}

\begin{tabular}{|c|c|c|}
\hline & \multicolumn{2}{|c|}{ GAME 2} \\
\hline & $\begin{array}{c}\text { Player } Y \text { Will } \\
\text { Receive }\end{array}$ & $\begin{array}{c}\text { Player } Z \text { Will } \\
\text { Receive }\end{array}$ \\
\hline A & $\mathbf{5 0 ~ c e n t s ~}$ & $\mathbf{5 0}$ cents \\
\hline B & $\mathbf{5 0}$ cents & 10 cents \\
\hline
\end{tabular}

Now, please make your decision in this game (by choosing A or B) given that:

- If you choose A, Player $Y$ will receive 50 cents regardless of which game you are in, and Player $Z$ will receive 10 cents if you are in GAME 1 or 50 cents if you are in GAME 2.

- If you choose B, Player $Y$ will receive 50 cents regardless of which game you are in, and Player $Z$ will receive 50 cents if you are in GAME 1 or 10 cents if you are in GAME 2. 


\section{B.4 Experimental Instructions for Study 4}

Participants in Study 4 are randomly assigned to 1 of 4 conditions that arise from Hidden Information $\times($ Self/Other, Other/Other $) \times($ Unaligned state, Aligned state $)$. That is, they are always assigned to a Hidden Information condition.

After consenting to participate in the study, participants are informed of the study completion fee and of the opportunity to earn an additional payment, as shown in Figure B.44. 
Figure B.44: Study 4 Payment Information

Your Payment: This study involves 3 decisions that ask you to choose between different payment options, followed by a short survey. There is 1 in 3 chance (or $33 \%$ chance) that one of these decisions will be randomly selected as the decision-that-counts. If one of your decisions is randomly selected as the decision-that-counts, whichever payment option you choose in the decision-that-counts will be distributed as additional payment from this study. More specifically:

If you choose a payment option that benefits you in the decision-that-counts, the corresponding additional payment will be given to you in cash at the end of this study.

If you choose a payment option that benefits some other person in the decision-thatcounts, the corresponding additional payment will be given to that other person.

The other people: Throughout this study, you will be matched with two other people who will be called "Player Y" and "Player Z." If one of your decisions is selected as a decisionthat-counts, the payment option you choose in the decision-that-counts may benefit Player Y, Player Z, both Player Y and Player Z, or neither Player Y nor Player Z.

Player $\mathrm{Y}$ and Player $\mathrm{Z}$ will be two unique MTurk workers. MTurk workers are individuals who we hire to complete surveys for us via an online platform called Amazon Mechanical Turk (MTurk), which "is a crowdsourcing marketplace that makes it easier for individuals and businesses to outsource their processes and jobs to a distributed workforce who can perform these tasks virtually" (https://www.mturk.com).

Understanding Question: Which of the following statements is true?

All of my decisions will influence the resulting payments from this study.

None of my decisions will influence the resulting payments from this study.

One of my decisions will influence the resulting payments from this study.

If one of my decisions is randomly selected as a decision-that-counts, that decision will influence the payments from this study. 
Participants are then provided with instructions about their decisions and asked comprehension questions. Figures B.45-B.46 show the instructions and comprehension questions for each of the conditions. 
Figure B.45: Decision 1: Hidden Information $\times$ Self/Other, Comprehension Question

\section{Decision 1 out of 3:}

Instructions for the game in this decision: You must choose A or B, which corresponds to payoffs for you and Player $Z$. Thus, the decision you make in this game will not influence payoffs for Player $Y$.

There is a $50 \%$ chance that you are in GAME 1 and a $50 \%$ that you are in GAME 2.

Both games are the same except that Player Z's payoffs are flipped between the two games. In particular:

- You will receive $\$ \mathbf{6}$ if you choose $\mathbf{A}$ in either game.

- You will receive $\$ \mathbf{5}$ if you choose $\mathbf{B}$ in either game.

- Player $\mathbf{Z}$ will receive $\$ 1$ if you choose $\mathbf{A}$ in GAME 1 or $\mathbf{B}$ in GAME 2.

- Player $\mathbf{Z}$ will receive $\$ 5$ if you choose $\mathbf{B}$ in GAME 1 or $\mathbf{A}$ in GAME 2.

Put differently, according to whether you are in GAME 1 or GAME 2 and whether you choose A or B, the payoffs for you and Player Z can be described as follows:

\begin{tabular}{|c|c|c|}
\hline & \multicolumn{2}{|c|}{ GAME 1 } \\
\hline & $\begin{array}{c}\text { You Will } \\
\text { Receive }\end{array}$ & $\begin{array}{c}\text { Player } \mathrm{Z} \text { Will } \\
\text { Receive }\end{array}$ \\
\hline $\mathrm{A}$ & $\$ 6$ & $\$ 1$ \\
\hline $\mathrm{B}$ & $\$ 5$ & $\$ 5$ \\
\hline
\end{tabular}

\begin{tabular}{|c|c|c|}
\hline & \multicolumn{2}{|c|}{ GAME 2 } \\
\hline & $\begin{array}{c}\text { You Will } \\
\text { Receive }\end{array}$ & $\begin{array}{c}\text { Player Z Will } \\
\text { Receive }\end{array}$ \\
\hline A & $\$ 6$ & $\$ 5$ \\
\hline$B$ & $\$ 5$ & $\$ 1$ \\
\hline
\end{tabular}

Understanding Question: You will receive more money if. . .

$$
\text { you choose } \mathrm{A} \text { in either game. }
$$

you choose B in either game.

you choose A in GAME 1 or B in GAME 2.

you choose B in GAME 1 or A in GAME 2.

Understanding Question: Player Z will receive more money if. . .

you choose $\mathrm{A}$ in either game.

you choose B in either game.

you choose A in GAME 1 or B in GAME 2.

you choose B in GAME 1 or A in GAME 2. 
Figure B.46: Decision 1: Hidden Information $\times$ Other/Other, Comprehension Question

\section{Decision 1 out of 3:}

Instructions for the game in this decision: You must choose A or B, which corresponds to payoffs for Player $Y$ and Player $Z$. Thus, the decision you make in this game will not influence payoffs for you.

There is a $50 \%$ chance that you are in GAME 1 and a $50 \%$ that you are in GAME 2.

Both games are the same except that Player Z's payoffs are flipped between the two games. In particular:

- Player $\mathbf{Y}$ will receive $\$ 6$ if you choose $\mathbf{A}$ in either game.

- Player $\mathbf{Y}$ will receive $\$ \mathbf{5}$ if you choose $\mathbf{B}$ in either game.

- Player $\mathbf{Z}$ will receive $\$ 1$ if you choose $\mathbf{A}$ in GAME 1 or $\mathbf{B}$ in GAME 2.

- Player $\mathbf{Z}$ will receive $\$ 5$ if you choose $\mathbf{B}$ in GAME 1 or $\mathbf{A}$ in GAME 2.

Put differently, according to whether you are in GAME 1 or GAME 2 and whether you choose $\mathrm{A}$ or $\mathrm{B}$, the payoffs for Player $\mathrm{Y}$ and $\mathrm{Player} \mathrm{Z}$ can be described as follows:

\begin{tabular}{|c|c|c|}
\hline & \multicolumn{2}{|c|}{ GAME 1 } \\
\hline & $\begin{array}{c}\text { Player Y Will } \\
\text { Receive }\end{array}$ & $\begin{array}{c}\text { Player Z Will } \\
\text { Receive }\end{array}$ \\
\hline A & $\$ 6$ & $\$ 1$ \\
\hline B & $\$ 5$ & $\$ 5$ \\
\hline
\end{tabular}

\begin{tabular}{|c|c|c|}
\hline & \multicolumn{2}{|c|}{ GAME 2 } \\
\hline & $\begin{array}{c}\text { Player Y Will } \\
\text { Receive }\end{array}$ & $\begin{array}{c}\text { Player Z Will } \\
\text { Receive }\end{array}$ \\
\hline A & $\$ 6$ & $\$ 5$ \\
\hline B & $\$ 5$ & $\$ 1$ \\
\hline
\end{tabular}

Understanding Question: Player $\mathrm{Y}$ will receive more money if. . .

you choose $\mathrm{A}$ in either game.

you choose $B$ in either game.

you choose $A$ in GAME 1 or $B$ in GAME 2.

you choose $B$ in GAME 1 or $A$ in GAME 2.

Understanding Question: Player Z will receive more money if. . .

you choose $\mathrm{A}$ in either game.

you choose $B$ in either game.

you choose $A$ in GAME 1 or B in GAME 2.

you choose B in GAME 1 or A in GAME 2. 
Participants are then reminded of the instructions and asked to make their first decision. The first decision always involves making a decision in the Hidden Information condition, since information avoidance is our main outcome of interest. Figures B.47-B.48 show the decision screens for each of the conditions. If participants in those conditions choose to Reveal Player Z's payoffs, the state is revealed on the next page, and they are asked to make their decision, as shown below in Figures B.49-B.52. 


\title{
Figure B.47: Decision 1: Hidden Information $\times$ Self/Other, Decision
}

\author{
Decision 1 out of 3:
}

Instructions for the game in this decision: You must choose A or B, which corresponds to payoffs for you and Player $Z$. Thus, the decision you make in this game will not influence payoffs for Player $\mathrm{Y}$.

There is a $50 \%$ chance that you are in GAME 1 and a $50 \%$ that you are in GAME 2.

Both games are the same except that Player Z's payoffs are flipped between the two games. In particular:

- You will receive $\$ 6$ if you choose $\mathbf{A}$ in either game.

- You will receive $\$ \mathbf{5}$ if you choose $\mathbf{B}$ in either game.

- Player $\mathbf{Z}$ will receive $\$ 1$ if you choose $\mathbf{A}$ in GAME 1 or $\mathbf{B}$ in GAME 2.

- Player $\mathbf{Z}$ will receive $\$ 5$ if you choose $\mathbf{B}$ in GAME 1 or $\mathbf{A}$ in GAME 2.

Put differently, according to whether you are in GAME 1 or GAME 2 and whether you choose $\mathrm{A}$ or $\mathrm{B}$, the payoffs for you and Player $\mathrm{Z}$ can be described as follows:

\begin{tabular}{|c|c|c|}
\hline & \multicolumn{2}{|c|}{ GAME 1 } \\
\hline & $\begin{array}{c}\text { You Will } \\
\text { Receive }\end{array}$ & $\begin{array}{c}\text { Player Z Will } \\
\text { Receive }\end{array}$ \\
\hline A & $\$ 6$ & $\$ 1$ \\
\hline B & $\$ 5$ & $\$ 5$ \\
\hline
\end{tabular}

\begin{tabular}{|c|c|c|}
\hline & \multicolumn{2}{|c|}{ GAME 2 } \\
\hline & $\begin{array}{c}\text { You Will } \\
\text { Receive }\end{array}$ & $\begin{array}{c}\text { Player Z Will } \\
\text { Receive }\end{array}$ \\
\hline A & $\$ 6$ & $\$ 5$ \\
\hline B & $\$ 5$ & $\$ 1$ \\
\hline
\end{tabular}

Now, please make your decision in this game (by choosing A or B) or instead indicate that you would like to make your decision after being informed of which game you are in (by choosing Reveal Player Z's Payoffs) given that:

- If you choose $\mathbf{A}$, you will receive $\$ 6$ regardless of which game you are in, and Player $Z$ will receive $\$ 1$ if you are in GAME 1 or $\$ 5$ if you are in GAME 2.

- If you choose B, you will receive $\$ 5$ regardless of which game you are in, and Player $Z$ will receive $\$ 5$ if you are in GAME 1 or $\$ 1$ if you are in GAME 2.

- If you choose Reveal Player Z's Payoffs, information on the next page will reveal whether you are in GAME 1 or GAME 2 and thus will reveal the exact payoffs that Player $\mathrm{Z}$ will receive if you choose $\mathrm{A}$ or $\mathrm{B}$. After this information is revealed, you will choose between $\mathrm{A}$ and $\mathrm{B}$. 
Figure B.48: Decision 1: Hidden Information $\times$ Other/Other, Decision

\section{Decision 1 out of 3 :}

Instructions for the game in this decision: You must choose A or B, which corresponds to payoffs for Player $Y$ and Player $Z$. Thus, the decision you make in this game will not influence payoffs for you.

There is a $50 \%$ chance that you are in GAME 1 and a $50 \%$ that you are in GAME 2.

Both games are the same except that Player Z's payoffs are flipped between the two games. In particular:

- Player $\mathbf{Y}$ will receive $\$ 6$ if you choose $\mathbf{A}$ in either game.

- Player $\mathbf{Y}$ will receive $\$ 5$ if you choose $\mathbf{B}$ in either game.

- Player $\mathbf{Z}$ will receive $\$ 1$ if you choose $\mathbf{A}$ in GAME 1 or $\mathbf{B}$ in GAME 2.

- Player $\mathbf{Z}$ will receive $\$ 5$ if you choose $\mathbf{B}$ in GAME 1 or $\mathbf{A}$ in GAME 2.

Put differently, according to whether you are in GAME 1 or GAME 2 and whether you choose $\mathrm{A}$ or $\mathrm{B}$, the payoffs for Player $\mathrm{Y}$ and Player $\mathrm{Z}$ can be described as follows:

\begin{tabular}{|c|c|c|}
\hline & \multicolumn{2}{|c|}{ GAME 1 } \\
\hline & $\begin{array}{c}\text { Player Y Will } \\
\text { Receive }\end{array}$ & $\begin{array}{c}\text { Player Z Will } \\
\text { Receive }\end{array}$ \\
\hline A & $\$ 6$ & $\$ 1$ \\
\hline B & $\$ 5$ & $\$ 5$ \\
\hline
\end{tabular}

\begin{tabular}{|c|c|c|}
\hline & \multicolumn{2}{|c|}{ GAME 2 } \\
\hline & $\begin{array}{c}\text { Player Y Will } \\
\text { Receive }\end{array}$ & $\begin{array}{c}\text { Player Z Will } \\
\text { Receive }\end{array}$ \\
\hline A & $\$ 6$ & $\$ 5$ \\
\hline B & $\$ 5$ & $\$ 1$ \\
\hline
\end{tabular}

Now, please make your decision in this game (by choosing A or B) or instead indicate that you would like to make your decision after being informed of which game you are in (by choosing Reveal Player Z's Payoffs) given that:

- If you choose A, Player $Y$ will receive $\$ 6$ regardless of which game you are in, and Player $Z$ will receive $\$ 1$ if you are in GAME 1 or $\$ 5$ if you are in GAME 2.

- If you choose $B$, Player $Y$ will receive $\$ 5$ regardless of which game you are in, and Player $Z$ will receive $\$ 5$ if you are in GAME 1 or $\$ 1$ if you are in GAME 2.

- If you choose Reveal Player Z's Payoffs, information on the next page will reveal whether you are in GAME 1 or GAME 2 and thus will reveal the exact payoffs that Player $\mathrm{Z}$ will receive if you choose $\mathrm{A}$ or $\mathrm{B}$. After this information is revealed, you will choose between $\mathrm{A}$ and $\mathrm{B}$. 
Figure B.49: Decision 1: Hidden Information $\times$ Self/Other $\times$ Aligned State, After Revealing Player Z's Payoffs

You chose to Reveal Player Z's Payoffs. Note that you are in GAME 2 and thus:

- You will receive $\$ 6$ if you choose $\mathbf{A}$.

- You will receive $\$ 5$ if you choose $\mathbf{B}$.

- Player $\mathbf{Z}$ will receive $\$ \mathbf{5}$ if you choose $\mathbf{A}$.

- Player $\mathbf{Z}$ will receive $\$ \mathbf{1}$ if you choose $\mathbf{B}$.

Put differently, since you are in GAME 2, according to whether you choose A or B, the payoffs for you and Player $Z$ can be described as follows:

\begin{tabular}{|c|c|c|}
\hline & \multicolumn{2}{|c|}{ GAME 2 } \\
\hline & $\begin{array}{c}\text { You Will } \\
\text { Receive }\end{array}$ & $\begin{array}{c}\text { Player } \mathbf{Z} \text { Will } \\
\text { Receive }\end{array}$ \\
\hline A & $\$ 6$ & $\$ 5$ \\
\hline$B$ & $\$ 5$ & $\$ 1$ \\
\hline
\end{tabular}

Now, please make your decision in this game (by choosing A or B) given that:

- If you choose $\mathbf{A}$, you will receive $\$ 6$, and Player $Z$ will receive $\$ 5$.

- If you choose $B$, you will receive $\$ 5$, and Player $Z$ will receive $\$ 1$. 
Figure B.50: Decision 1: Hidden Information $\times$ Self/Other $\times$ Unaligned State, After Revealing Player Z's Payoffs

You chose to Reveal Player Z's payoffs. Note that you are in GAME 1 and thus:

- You will receive $\$ 6$ if you choose $\mathbf{A}$.

- You will receive $\$ \mathbf{5}$ if you choose $\mathbf{B}$.

- Player $\mathbf{Z}$ will receive $\$ \mathbf{1}$ if you choose $\mathbf{A}$.

- Player $\mathbf{Z}$ will receive $\$ \mathbf{5}$ if you choose $\mathbf{B}$.

Put differently, since you are in GAME 1, according to whether you choose A or B. the payoffs for you and Player $Z$ can be described as follows:

\begin{tabular}{|c|c|c|}
\hline & \multicolumn{2}{|c|}{ GAME 1 } \\
\hline & $\begin{array}{c}\text { You Will } \\
\text { Receive }\end{array}$ & $\begin{array}{c}\text { Player Z Will } \\
\text { Receive }\end{array}$ \\
\hline A & $\$ 6$ & $\$ 1$ \\
\hline B & $\$ 5$ & $\$ 5$ \\
\hline
\end{tabular}

Now, please make your decision in this game (by choosing A or B) given that:

- If you choose $\mathbf{A}$, you will receive $\$ 6$, and Player $Z$ will receive $\$ 1$.

- If you choose $\mathbf{B}$, you will receive $\$ 5$, and Player $Z$ will receive $\$ 5$. 
Figure B.51: Decision 1: Hidden Information $\times$ Other/Other $\times$ Aligned State, After Revealing Player Z's Payoffs

You chose to Reveal Player Z's Payoffs. Note that you are in GAME 2 and thus:

- Player $\mathbf{Y}$ will receive $\$ 6$ if you choose $\mathbf{A}$.

- Player $\mathbf{Y}$ will receive $\$ \mathbf{5}$ if you choose $\mathbf{B}$.

- Player $\mathbf{Z}$ will receive $\$ 5$ if you choose $\mathbf{A}$.

- Player $\mathbf{Z}$ will receive $\$ \mathbf{1}$ if you choose $\mathbf{B}$.

Put differently, since you are in GAME 2, according to whether you choose A or B, the payoffs for Player $Y$ and Player $Z$ can be described as follows:

\begin{tabular}{|c|c|c|}
\hline & \multicolumn{2}{|c|}{ GAME 2 } \\
\hline & $\begin{array}{c}\text { Player Y Will } \\
\text { Receive }\end{array}$ & $\begin{array}{c}\text { Player Z Will } \\
\text { Receive }\end{array}$ \\
\hline A & $\$ 6$ & $\$ 5$ \\
\hline B & $\$ 5$ & $\$ 1$ \\
\hline
\end{tabular}

Now, please make your decision in this game (by choosing A or B) given that:

- If you choose $\mathbf{A}$, Player $Y$ will receive $\$ 6$, and Player $Z$ will receive $\$ 5$.

- If you choose $\mathbf{B}$, Player $Y$ will receive $\$ 5$, and Player $Z$ will receive $\$ 1$. 
Figure B.52: Decision 1: Hidden Information $\times$ Other/Other $\times$ Unaligned State, After Revealing Player Z's Payoffs

You chose to Reveal Player Z's payoffs. Note that you are in GAME 1 and thus:

- Player $\mathbf{Y}$ will receive $\$ 6$ if you choose $\mathbf{A}$.

- Player $\mathbf{Y}$ will receive $\$ 5$ if you choose $\mathbf{B}$.

- Player $\mathbf{Z}$ will receive $\mathbf{\$ 1}$ if you choose $\mathbf{A}$.

- Player $\mathbf{Z}$ will receive $\$ \mathbf{5}$ if you choose $\mathbf{B}$.

Put differently, since you are in GAME 1, according to whether you choose A or B. the payoffs for Player $Y$ and Player $Z$ can be described as follows:

\begin{tabular}{|c|c|c|}
\hline & \multicolumn{2}{|c|}{ GAME 1 } \\
\hline & $\begin{array}{c}\text { Player Y Will } \\
\text { Receive }\end{array}$ & $\begin{array}{c}\text { Player Z Will } \\
\text { Receive }\end{array}$ \\
\hline A & $\$ 6$ & $\$ 1$ \\
\hline B & $\$ 5$ & $\$ 5$ \\
\hline
\end{tabular}

Now, please make your decision in this game (by choosing A or B) given that:

- If you choose A, Player $Y$ will receive $\$ 6$, and Player $Z$ will receive $\$ 1$.

- If you choose $\mathbf{B}$, Player $Y$ will receive $\$ 5$, and Player $Z$ will receive $\$ 5$. 
Participants then face two more decisions in a random order. These two decisions may provide some insight related to how participants make decisions in the Known Information condition, but participants only ever made these decisions after they make decisions in the Hidden Information condition, so these latter two decisions could be influenced by their decisions in the Hidden Information condition. As explained in the main text, this design choice reflected our limited subject pool for Study 4 and our desire to focus on information avoidance decisions in the Hidden Information condition. Figures B.53-B.60 show the comprehension questions and subsequent two decisions.

Figure B.53: Decision 2: Self/Other, Comprehension Questions

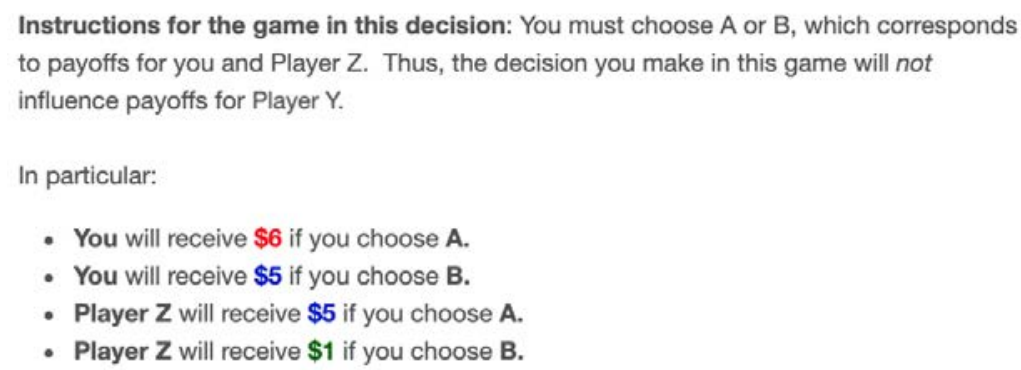

Put differently, according to whether you choose A or B, the payoffs for you and Player Z can be described as follows:

\begin{tabular}{|c|c|c|}
\hline & $\begin{array}{c}\text { You Will } \\
\text { Receive }\end{array}$ & $\begin{array}{c}\text { Player } \mathbf{Z} \text { Will } \\
\text { Receive }\end{array}$ \\
\hline A & $\$ 6$ & $\$ 5$ \\
\hline B & $\$ 5$ & $\$ 1$ \\
\hline
\end{tabular}

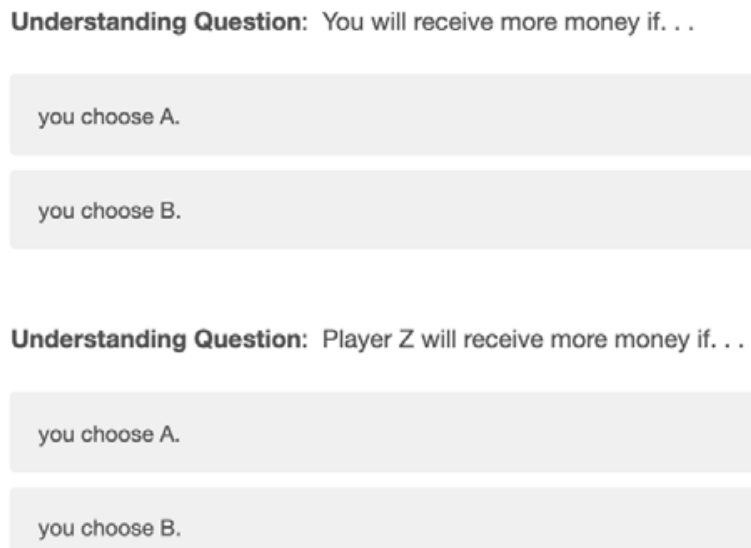


Figure B.54: Decision 2: Self/Other, Decision

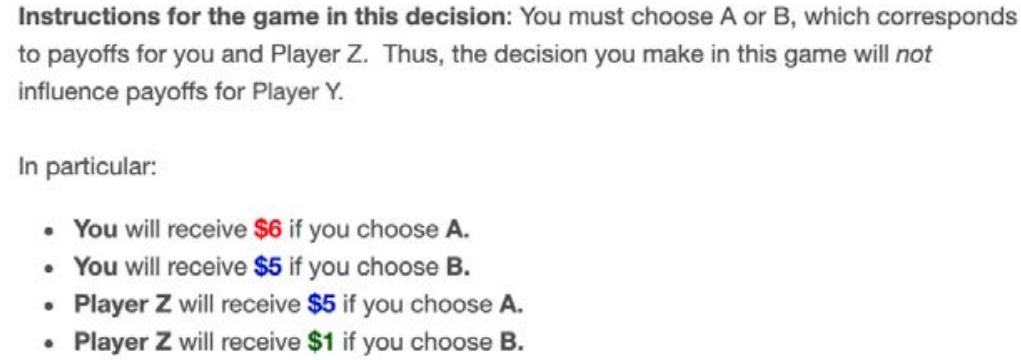

Put differently, according to whether you choose A or B, the payoffs for you and Player Z can be described as follows:

\begin{tabular}{|c|c|c|}
\hline & $\begin{array}{c}\text { You Will } \\
\text { Receive }\end{array}$ & $\begin{array}{c}\text { Player } \mathbf{Z} \text { Will } \\
\text { Receive }\end{array}$ \\
\hline A & $\$ 6$ & $\$ 5$ \\
\hline B & $\$ 5$ & $\$ 1$ \\
\hline
\end{tabular}

Now, please make your decision in this game (by choosing A or B) given that:

- If you choose $\mathbf{A}$, you will receive $\$ 6$, and Player $Z$ will receive $\$ 5$.

- If you choose $B$, you will receive $\$ 5$, and Player $Z$ will receive $\$ 1$. 
Figure B.55: Decision 3: Self/Other, Comprehension Question

Instructions for the game in this decision: You must choose A or B, which corresponds to payoffs for you and Player $Z$. Thus, the decision you make in this game will not influence payoffs for Player $\mathrm{Y}$.

In particular:

- You will receive $\$ 6$ if you choose $\mathbf{A}$.

- You will receive $\$ 5$ if you choose $\mathbf{B}$.

- Player $\mathbf{Z}$ will receive $\$ 1$ if you choose $\mathbf{A}$.

- Player $\mathbf{Z}$ will receive $\$ 5$ if you choose $\mathbf{B}$.

Put differently, according to whether you choose A or B. the payoffs for you and Player Z can be described as follows:

\begin{tabular}{|c|c|c|}
\hline & $\begin{array}{c}\text { You Will } \\
\text { Receive }\end{array}$ & $\begin{array}{c}\text { Player } \mathbf{Z} \text { Will } \\
\text { Receive }\end{array}$ \\
\hline A & $\$ 6$ & $\$ 1$ \\
\hline B & $\$ 5$ & $\$ 5$ \\
\hline
\end{tabular}

Understanding Question: You will receive more money if. . .

you choose A.

you choose B.

Understanding Question: Player Z will receive more money if. . .

you choose $\mathrm{A}$.

you choose $B$. 
Figure B.56: Decision 3: Self/Other, Decision

Instructions for the game in this decision: You must choose A or B, which corresponds to payoffs for you and Player $Z$. Thus, the decision you make in this game will not influence payoffs for Player $Y$.

In particular:

- You will receive $\$ 6$ if you choose $\mathbf{A}$.

- You will receive $\$ 5$ if you choose B.

- Player $\mathbf{Z}$ will receive $\$ 1$ if you choose $\mathbf{A}$.

- Player $\mathbf{Z}$ will receive $\$ 5$ if you choose $\mathbf{B}$.

Put differently, according to whether you choose A or B. the payoffs for you and Player Z can be described as follows:

\begin{tabular}{|c|c|c|}
\hline & $\begin{array}{c}\text { You Will } \\
\text { Receive }\end{array}$ & $\begin{array}{c}\text { Player Z Will } \\
\text { Receive }\end{array}$ \\
\hline A & $\$ 6$ & $\$ 1$ \\
\hline B & $\$ 5$ & $\$ 5$ \\
\hline
\end{tabular}

Now, please make your decision in this game (by choosing A or B) given that:

- If you choose $A$, you will receive $\$ 6$, and Player $Z$ will receive $\$ 1$.

- If you choose $\mathbf{B}$, you will receive $\$ 5$, and Player $Z$ will receive $\$ 5$. 
Figure B.57: Decision 2: Other/Other, Comprehension Questions

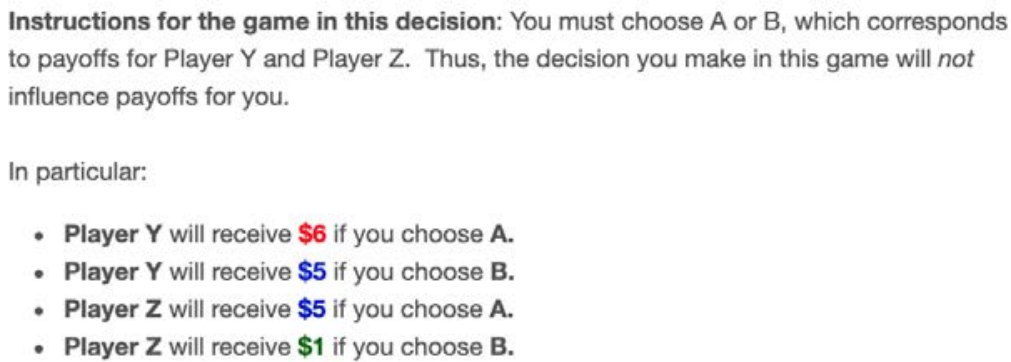

Put differently, according to whether you choose A or B, the payoffs for Player $\mathrm{Y}$ and Player $Z$ can be described as follows:

\begin{tabular}{|c|c|c|}
\hline & $\begin{array}{c}\text { Player } \mathbf{Y} \text { Will } \\
\text { Receive }\end{array}$ & $\begin{array}{c}\text { Player } \mathbf{Z} \text { Will } \\
\text { Receive }\end{array}$ \\
\hline A & $\$ 6$ & $\$ 5$ \\
\hline B & $\$ 5$ & $\$ 1$ \\
\hline
\end{tabular}

Understanding Question: Player $\mathrm{Y}$ will receive more money if. . .

you choose $\mathrm{A}$.

you choose B.

Understanding Question: Player Z will receive more money if. . .

you choose A.

you choose B. 
Figure B.58: Decision 2: Other/Other, Decision

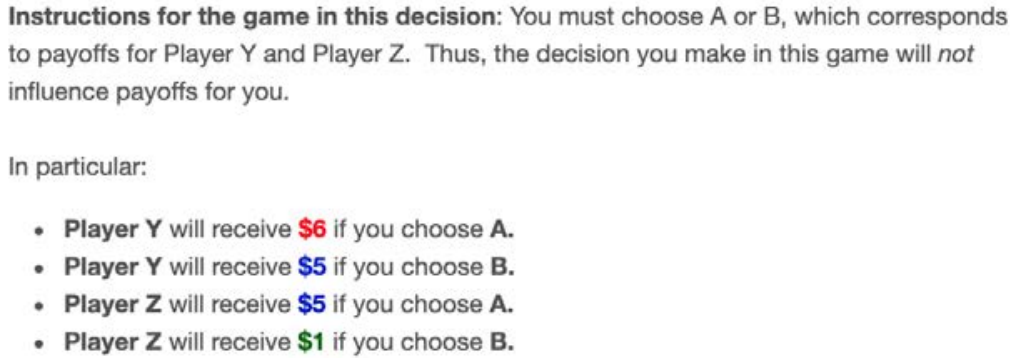

Put differently, according to whether you choose $\mathrm{A}$ or $\mathrm{B}$, the payoffs for Player $\mathrm{Y}$ and Player $Z$ can be described as follows:

\begin{tabular}{|c|c|c|}
\hline & $\begin{array}{c}\text { Player } \mathbf{Y} \text { Will } \\
\text { Receive }\end{array}$ & $\begin{array}{c}\text { Player } \mathbf{Z} \text { Will } \\
\text { Receive }\end{array}$ \\
\hline A & $\$ 6$ & $\$ 5$ \\
\hline B & $\$ 5$ & $\$ 1$ \\
\hline
\end{tabular}

Now, please make your decision in this game (by choosing A or B) given that:

- If you choose $A$, Player $Y$ will receive $\$ 6$, and Player $Z$ will receive $\$ 5$.

- If you choose $B$, Player $Y$ will receive $\$ 5$, and Player $Z$ will receive $\$ 1$. 
Figure B.59: Decision 3: Other/Other, Comprehension Questions

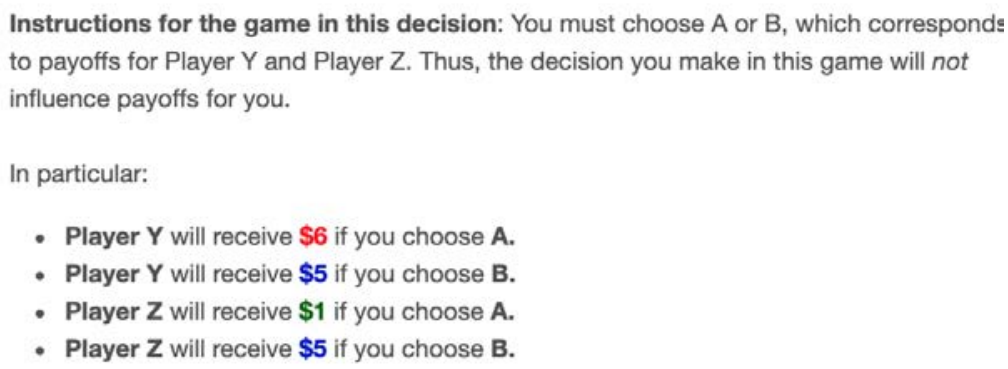

Put differently, according to whether you choose A or B. the payoffs for Player $\mathrm{Y}$ and Player $\mathrm{Z}$ can be described as follows:

\begin{tabular}{|c|c|c|}
\hline & $\begin{array}{c}\text { Player Y Will } \\
\text { Receive }\end{array}$ & $\begin{array}{c}\text { Player Z Will } \\
\text { Receive }\end{array}$ \\
\hline A & $\$ 6$ & $\$ 1$ \\
\hline B & $\$ 5$ & $\$ 5$ \\
\hline
\end{tabular}

Understanding Question: Player Y will receive more money if. . .

you choose $\mathrm{A}$

you choose B.

Understanding Question: Player Z will receive more money if. . .

you choose $\mathrm{A}$.

you choose B. 
Figure B.60: Decision 3: Other/Other, Decision

Instructions for the game in this decision: You must choose A or B, which corresponds to payoffs for Player $Y$ and Player $Z$. Thus, the decision you make in this game will not influence payoffs for you.

In particular:

- Player $\mathbf{Y}$ will receive $\$ 6$ if you choose $\mathbf{A}$.

- Player $\mathbf{Y}$ will receive $\$ \mathbf{5}$ if you choose $\mathbf{B}$.

- Player $\mathbf{Z}$ will receive $\$ \mathbf{1}$ if you choose $\mathbf{A}$.

- Player $\mathbf{Z}$ will receive $\$ \mathbf{5}$ if you choose $\mathbf{B}$.

Put differently, according to whether you choose A or B. the payoffs for Player $Y$ and Player $Z$ can be described as follows:

\begin{tabular}{|c|c|c|}
\hline & $\begin{array}{c}\text { Player Y Will } \\
\text { Receive }\end{array}$ & $\begin{array}{c}\text { Player } \mathbf{Z} \text { Will } \\
\text { Receive }\end{array}$ \\
\hline$A$ & $\$ 6$ & $\$ 1$ \\
\hline$B$ & $\$ 5$ & $\$ 5$ \\
\hline
\end{tabular}

Now, please make your decision in this game (by choosing A or B) given that:

- If you choose $\mathbf{A}$, Player $Y$ will receive $\$ 6$, and Player $Z$ will receive $\$ 1$.

- If you choose $\mathbf{B}$, Player $Y$ will receive $\$ 5$, and Player $Z$ will receive $\$ 5$. 